\title{
A Pulsating Heat Pipe Embedded Radiator: Thermal-Vacuum Characterisation in the Pre-Cryogenic Temperature Range for Space Applications
}

\author{
Luca Pietrasanta ${ }^{1,2,3}$, Giovanni Postorino ${ }^{1}$, Roberta Perna1, ${ }^{1}$ Mauro Mameli ${ }^{* *}$, Sauro \\ Filippeschi ${ }^{1}$
}

\author{
${ }^{1}$ Department of Energy, Systems Land and Construction Engineering, University of Pisa, Largo L. Lazzarino, Pisa, Italy. \\ ${ }^{2}$ School of Computing, Engineering and Mathematics, University of Brighton, Lewes Road, BN2 4GJ Brighton, UK. (Permanent address). \\ ${ }^{3}$ Advance Engineering Centre, Lewes Road, BN2 4GJ, Brighton, UK \\ *E-mail of the corresponding Author (Mauro Mameli): mauro.mameli@unipi.it
}

\begin{abstract}
The use of Pulsating Heat Pipes (PHPs) in the space field is still an open issue because of the lack of data obtained during actual operation in relevant environment. A considerable amount of data is available in the literature on the thermal response of PHPs to a variable gravity condition and on the operation in the cryogenic field but in both cases the heat load at the condenser is rejected by convection to a constant temperature sink. On the other hand, barely any work in the PHP's literature deals with thermal radiation to a low temperature sink as only heat transfer mode. The present work attempts to fill the gap by testing a PHP radiator (16 turns, $1.1 \mathrm{~mm}$ inner diameter, $50 \%$ filled with FC-72 at 293K) in thermo-vacuum conditions in horizontal orientation at different heat loads and different environment (chamber) temperature. Fluid pressure measurements coupled with the frequency analysis characterised the effect of the cold source temperature on the device operational limits and efficiency. Results show that the device thermal performance in the radiative configuration is mostly affected by the lower operating temperatures needed to obtain a sensible heat rejection, rather than the heat transfer mode itself. The decrease of the environment temperature shortens the operational heat load range: the start-up occurs at higher heat input levels while the thermal crisis occurs at lower heat loads. The frequency analysis reveals that the equivalent thermal resistance is positively affected by higher values of the dominant frequency for all the cases.
\end{abstract}

Keywords: Pulsating Heat Pipe, Embedded Radiator, Thermal-Vacuum Chamber, Thermal Control System, Space Applications.

\section{Introduction}

Thermal Control Systems (TCSs) are critical sub-sections of a spacecraft [1], which require scientific attention to facilitate future Lunar landing and extra-planetary exploration. The development of new versatile TCSs is fundamental to maintain the spacecraft and the payload components within the required temperature limits during each phase of future missions planned by space agencies worldwide, enduring the space environment. From this perspective, future technologies for TCS must be efficient, compact, lightweight, reliable and adaptable to complex geometries. The integration of active technologies like mechanically pumped loops, cryocoolers, although common options in the space field, comes with a certain grade of 
complexity which increases the source of potential faults [2] and they require a source of energy throughout their operational life. For this reason, passive systems, such as Heat Pipes [3] and Loop Heat Pipes [4], have been used as fundamental components of TCS in space missions since the late 1970 s and late 1990 s respectively and consolidated their position as the most reliable in the plethora of TCS available to space engineers to cover demanding tasks [5]. The last two decades witnessed a growing interest worldwide towards the development of a new device of the Heat Pipe family: the Pulsating Heat Pipe (PHP) [6] [7], given the advantages of having no wick structures (reduced weight, reduce costs, no entrainment limit). PHPs are currently exploited in numerous on-ground applications like heat removal form power electronics [8], waste heat recovery [9], photovoltaic (PV) cooling [10] and cryogenics [11]. In terms of operating temperature ranges, the researchers mainly concentrated towards ground applications in the high temperature ranges $273 \mathrm{~K}$ to $400 \mathrm{~K}$ and in the cryogenic range $(20 \mathrm{~K}$ to $100 \mathrm{~K}$ ), leaving almost unexplored the range of temperature in between the two. Despite this range covers a very wide span of the thermal requirements of spacecraft thermal components, as shown in Figure 1, just a few works in the pre-cryogenic temperature range are available for PHPs and none of them have been characterized in purely radiative heat transfer conditions (thermo-vacuum). Chen et al. [12] stressed this lack of experimental data too, concluding that the operating characteristics of PHPs in mid-low temperature range have been barely investigated. In their work, an ethane filled PHP (Copper tube, $2 \mathrm{~mm} / 3 \mathrm{~mm}$ I.D./O.D., 10 turns) has been coupled to a Stirling cooler to obtain a variable condenser temperature in the range $273 \mathrm{~K}$ to $183 \mathrm{~K}$, but not operating in a reduced temperature environment (the experiment is not in a climate chamber). The power input has been varied from $10 \mathrm{~W}$ to $50 \mathrm{~W}$ as well as the inclination angle $\left(0^{\circ}, 30^{\circ}, 45^{\circ}, 60^{\circ}\right.$ and $\left.90^{\circ}\right)$. The effect of the filling ratio on the equivalent thermal resistance has been explored as well $(22 \%, 30 \%, 40 \%, 50 \%, 60 \%)$. They concluded that the optimal filling ratio did not change with the power input in the range of temperature explored and they identified better performance for a specific condenser temperature (193 K). the optimal filling ratio is a function of the thermal properties of the working fluid, as demonstrated by Torresin et al. [13], where the authors carried out an experimental characterization of an open-loop PHP for automotive applications in a climatic chamber (controlled atmospheric temperature between $213 \mathrm{~K}$ to $333 \mathrm{~K}$ ), with fixed cooling airflow and heat power density ranging between 3 and $13 \mathrm{~W} / \mathrm{cm}^{2}$. Indeed, for the two fluids tested (R134a and R245fa), different optimal filling ratio has been identified. In both [12] and [13] the authors highlight the critical role of the viscosity, which can lead to degradation of the thermal performance of the PHP. It is then important to explore wider temperature ranges for commonly used fluids in PHPs and observe their functioning and potential limitations caused by viscous dissipation.

For their flexibility and achievable thermal conductance, PHPs can be seen as the perfect radiator-embedded heat transfer medium, able to transfer a significant amount of heat from a heat source (i.e. power electronics located inside a satellite), where the evaporation takes place, and transfer it to the heat sink (i.e. a radiator, facing deep space), where the fluid condenses and the heat can be disposed. Once the fluid returns to the evaporator, the PHP cycle is completed. 


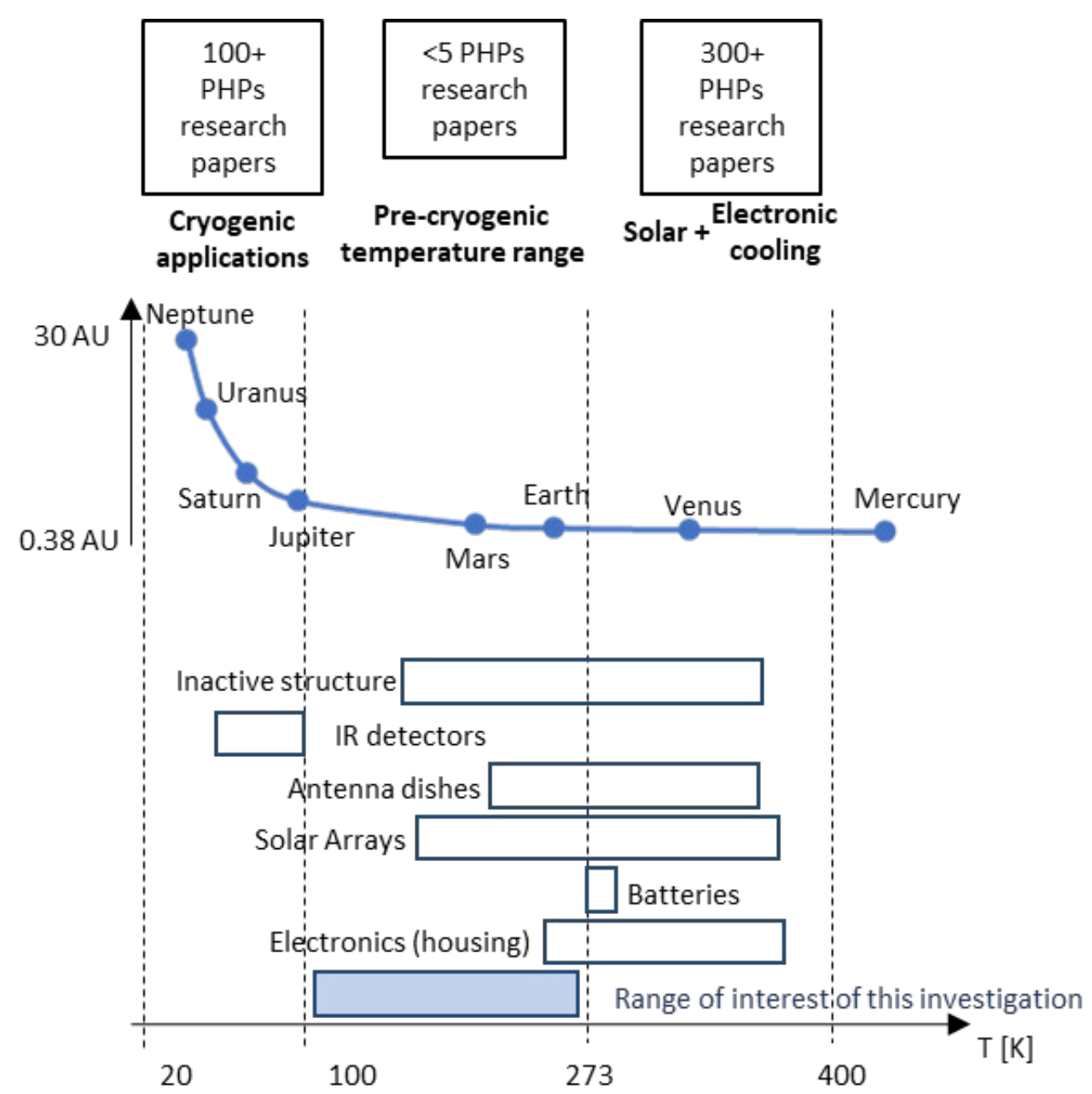

Figure 1: Research papers on PHP by range of operating temperature (above). Temperature of a black sphere exposed to sunlight at the distance of the different planets from the Sun [14] (blue dots). Examples of typical thermal requirements for space components [15] (below).

The idea of an embedded tubular PHP thermal radiator has been firstly proposed by Hemadri et al. [16] (copper tube; I.D./O.D. = 2mm/3mm; DI Water, Ethanol; FR: $60 \%$ ) but not completely explored, especially for space applications; they estimated the thermal resistance of the resulting device in the range of temperature from $293 \mathrm{~K}$ to $393 \mathrm{~K}$, showing that the degree of isothermalisation achieved with an embedded PHP strongly depends on the Biot number. The embedded PHP structures effect was appreciably higher when the thermal conductivity of the radiator plate material was low.

For space applications, the ability to achieve low equivalent thermal resistance without the assistance of gravity nor the presence of a porous wick to help the return of the condensate attracted the attention of many research groups. The PHP characterization in space environment has just begun in the last few years, supported by research programmes also from space agencies and scientific research organisations, like the ESA Microgravity Application Programme, which funded the project on Innovative wickless heat pipes for ground and space applications (INWIP) [17] [18] [19], the two on-orbit technology demonstrators from U.S. Air Force Research Laboratory STP-H4-ATT [20] and JAXA SDS-4 [21], with the aim of increasing the TRL of the technology. Due to the complexity of experimental research in space, the two demonstrators could prove their long-term reliable operation with a single set of parameters, but a thorough thermal characterization was intrinsically not possible. Although Akachi's first 
patent dates back to 1990 and the large amount of papers available in the literature on the topic, the PHP is still considered a relatively new technology because its governing phenomena are not completely understood yet. A relative good number of works have explored the effect of gravity on the overall thermal performance and on the hydro-dynamics underpinning the pulsating slug-plug flow required to operate a PHP; thermal characterisations in relevant gravity environment thanks to the available short-term microgravity platforms (e.g. parabolic flight, sounding rocket, satellite), have been done by several research groups ([17] [18] [19] [20] [21]) showing that the thermal performance of a capillary PHP on ground in the horizontal position is comparable to the one in microgravity [22] [23] and showing that a device with an internal diameter which is larger than the capillary limit works, to a certain extent, as a PHP in weightlessness conditions [17] [18] [24]. An experimental work under microgravity conditions with a structurally-embedded Flat Plate PHP (Aluminium; $1.3 \times 1.3 \mathrm{~mm} 2 ; 20$ turns; Acetone, FR $80 \%$ ) has been done by Taft et al. [25], but the heat sink was provided by a cold plate connected to a thermal bath. All the characterizations done so far in microgravity conditions, concentrated only on the device thermal response to the occurrence of weightlessness but did not cover the space temperature range and neither the heat exchange by radiation. As a result, a lack in the existing body of literature has been identified in testing radiator-embedded PHPs in a low-temperature range $(100 \mathrm{~K}$ to $273 \mathrm{~K})$ and simultaneously dissipating heat purely by radiation, in relevant thermal-vacuum conditions.

Exploiting the comparable functioning of a horizontal capillary PHP on ground to the one in microgravity, the experimental test cell previously tested onboard of the $58^{\text {th }}$ ESA Parabolic Flight Campaign [22], has been reconditioned and adapted to a new experimental campaign in thermal-vacuum conditions relevant to space applications. In order to explore the potentialities of a radiator-embedded PHP, the previous design has been modified to replace the convective cooling system with a radiative plate. This investigation aims at answering some basic physics questions related to the behaviour of commonly used fluids outside the conventional range of application in a purely radiative exchange mode, especially looking for start-up delays patterns and fluid oscillation hindering (blockage) with a decreasing ambient temperature. Attention is drawn on the existence of a hysteresis behaviour between heating and cooling cycles.

\section{Experimental set-up and procedure}

The experimental campaign conducted for this work aims at characterising the behaviour of a radiator-embedded Pulsating Heat Pipe for space applications, where the only mechanism allowed to reject waste heat towards the surrounding environment is radiative. In this framework, the novelties of this investigation are:

- The PHP rejects heat from the condenser relying only on radiative heat exchange. No convection is allowed thanks to the exposure of the cell to high-vacuum environment;

- The PHP is tested in a thermal-vacuum chamber (TVC) over a range of temperature not explored in literature;

The test-cell assembly is composed by two main sub-systems:

- The PHP test cell, with the heating system and the acquisition system;

- The radiator, fixed to the condenser of the PHP.

The set-up consist of the test-cell assembly, a thermal vessel and the Thermal Vacuum Chamber (TVC). The sub-systems of the test-cell assembly and their characteristics are described in the following paragraphs, along with the other components of the set-up. 


\subsection{The PHP test-cell}

The core of the set-up comes from the $58^{\circ}$ Parabolic Flight Campaign, where Mameli et al. [22], investigated the response of wall temperature and local fluid pressure to changes of gravity levels (between $0 \mathrm{~g}$ and $2 \mathrm{~g}$ ); the original design has undergone fundamental modifications to obtain a purely radiative heat exchange at the condenser. The test cell is connected to the main structure by means of rubber joints to minimize the conduction heat losses. Table 1 highlights the main features of the two set-ups. Starting from the features part also of the original design, the test-cell heating is obtained with a $0,5 \mathrm{~mm} \varnothing$ Thermocoax ${ }^{\circledR} 1 \mathrm{Nc}-\mathrm{Ac}(1 \mathrm{Nc}=$ Single core, without cold end; $A c=$ Austenitic stainless steel, low carbon content) wire electrical heater. The heaters are coiled on the PHP U-turns in contact with the evaporator region only and enclosed in a PEEK $^{\circledR}$ cover (not shown in Figure 2) to make sure all the heat input is directed to the test cell and not dissipated in the supporting structure. The PHP pipework (Figure 2) is a $203 \times 186 \mathrm{~mm}$ planar copper serpentine with 32 parallel channels (I.D./O.D. $=1.1 / 2.0 \mathrm{~mm}, 3 \mathrm{~mm}$ curvature radius) aligned $12 \mathrm{~mm}$ apart (channels interaxial distance) equipped with 14 wall-side type-T thermocouples (acquisition frequency 10Hz) and a pressure transducer (Kulite ${ }^{\circledR}$, ETL/T 312, 1.2 bar $\mathrm{A}$, acquisition frequency $100 \mathrm{~Hz}$ ) placed in the condenser. The pressure signal is acquired after the vacuum filling procedure and before the experiment to check whether the measurement corresponds to the fluid saturation pressure at room temperature, confirming the absence of non-condensable gases. Furthermore, the pressure signal is acquired during the experiment to infer about the nature of the fluid motion as explained in more detail in section 3.3 .

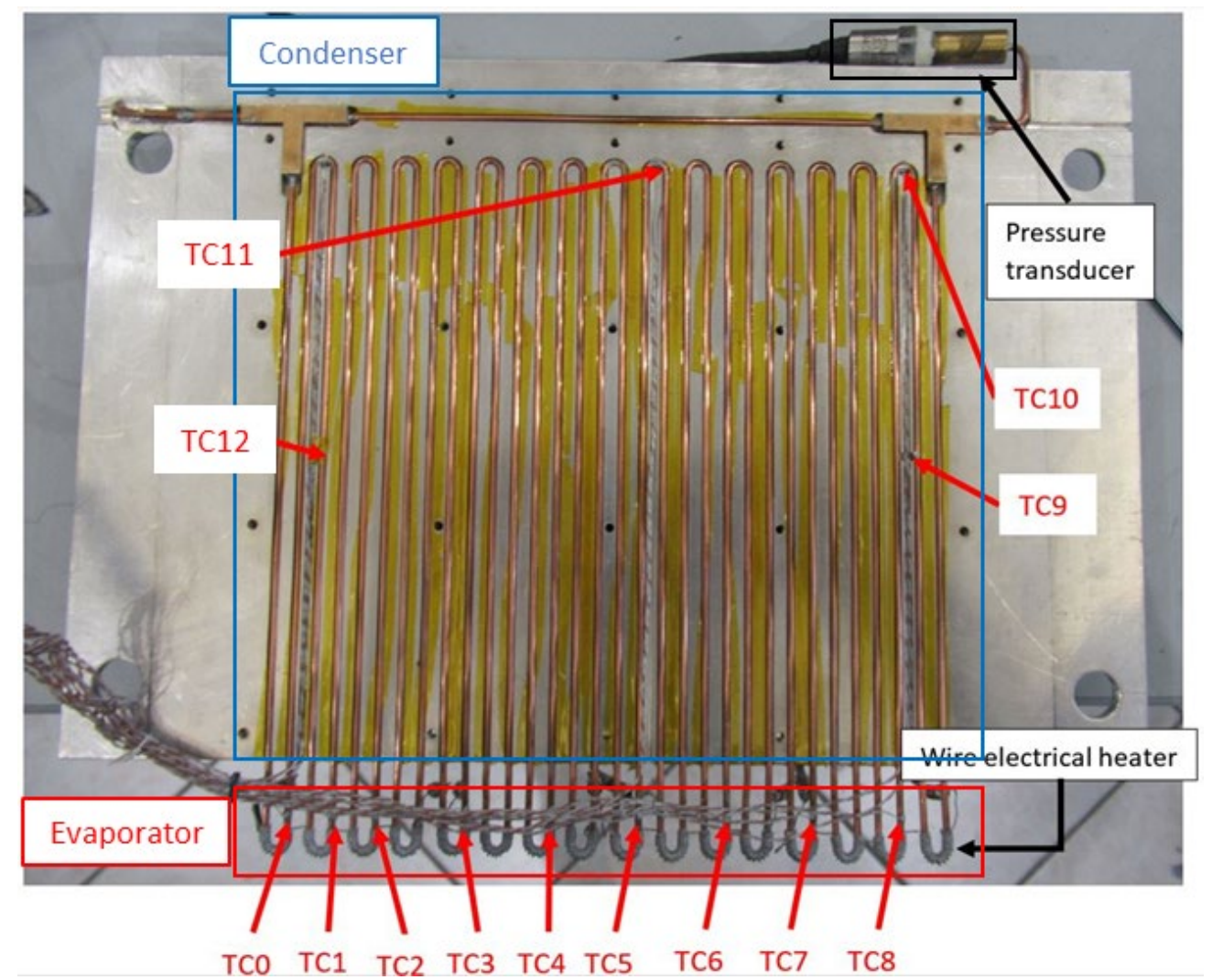

Figure 2: Test-cell geometry, main sections and sensors layout.

The PHP structure has been bent thanks to a custom-made pipe bending jig with the same geometry of the milled housing on the aluminium plate. The bending jig accommodated the malleable annealed copper tubing during the bending process. This allowed to obtain a planar 
2D displacement of the pipework, with a consistent bending radius and straightness of the pipes. The aluminium plate is milled with an hemispheric tool to guarantee a good thermal contact with the PHP tube. These sensors, together with the pressure transducer, are connected to the $\mathrm{NI}^{\circledR}$ c-RIO 9073 data acquisition system. The PHP is filled with FC-72 as working fluid with a $50 \%$ volumetric filling ratio. A sensitivity analysis on the filling ratio has been performed by the authors in a previous work with the same geometry and fluid [26].

Table 1: Changes in the set-up between this investigation and the design for the $58^{\text {th }}$ PFC

\begin{tabular}{l|l|l} 
& \multicolumn{1}{|c}{$58^{\text {th }}$ PFC $([22])$} & This work \\
\hline Heat Source & \multicolumn{2}{|c}{ Wire electrical heaters } \\
\hline PHP & \multicolumn{2}{|c}{ Same design, fluid and filling ratio } \\
\hline Heat sink & Finned surface with fans & Radiator plate \\
\hline Cooling method & Forced convection & Pure radiation
\end{tabular}

\subsection{The radiator}

The section of the PHP where the condensation takes place covers $180 \mathrm{~mm}$ and is embedded inside two aluminium support plates to confer rigidity to the pipework. The bottom plate is milled with the same footprint of the serpentine, where the pipework is placed in a flushmounted fashion. The other plate (top plate) is a flat plain one, that secure in position the PHP and serves as fixing point for the actual radiator, an aluminium plate with thickness of $0.8 \mathrm{~mm}$ and footprint of $600 \times 700 \mathrm{~mm}$.

The thermal conduction between the PHP pipe and the bottom plate (that now has only structural function) is hindered by applying Kapton tape along the milled surface. The reader can notice a finned surface on which four fans were attached to the PFC experiment; all fans have been removed in the set-up objective of this investigation(Figure 3a). The contact thermal resistance between the condenser section of the PHP and the radiating plate is reduced thanks to a graphite thermal pad (PGS EYG-A ${ }^{\circledR}$, thickness $70 \mu \mathrm{m}$, planar thermal conductivity 1000 $\mathrm{W} / \mathrm{mK}$ ) since commercial thermal compounds are not allowed in TVCs. The pads are then screwed and kept in position underneath the radiator plate. The flat radiating plate is coated with a high-emissivity black paint (LabIR ${ }^{\circledR}$ Paint HEWP-LT-MWIR-BK-11) and fixed in position with screws in several locations (Figure $3 b$ ) to improve the thermal contact and to avoid bending of the surface due to the established thermal gradient while operating. One type$\mathrm{T}$ thermocouple is placed in the centre of the radiating surface and acquired synchronously with the other thermocouples placed on the PHP wall. 
a)

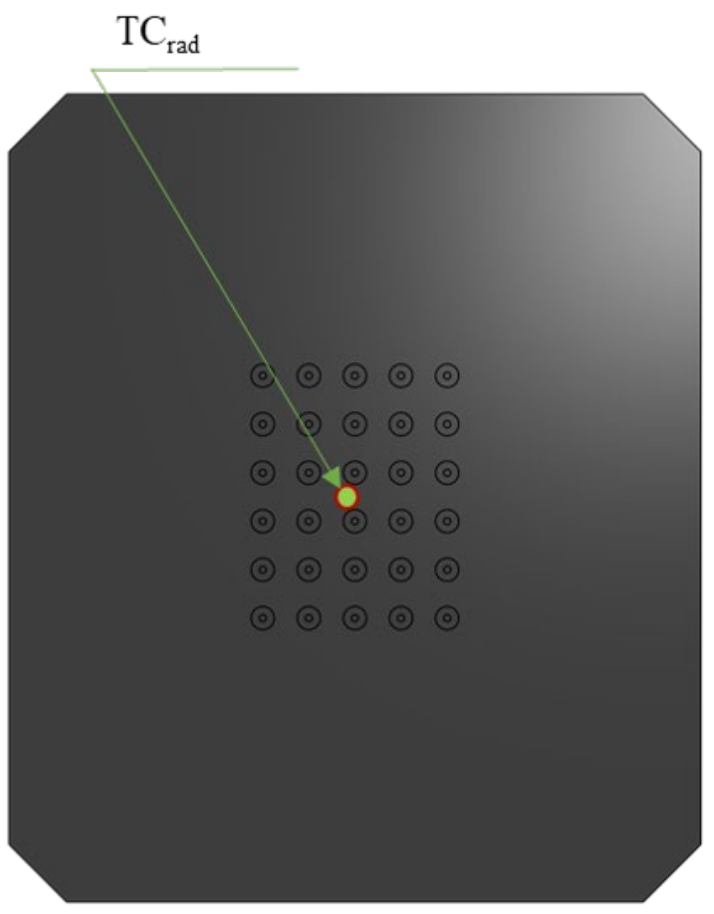

b)

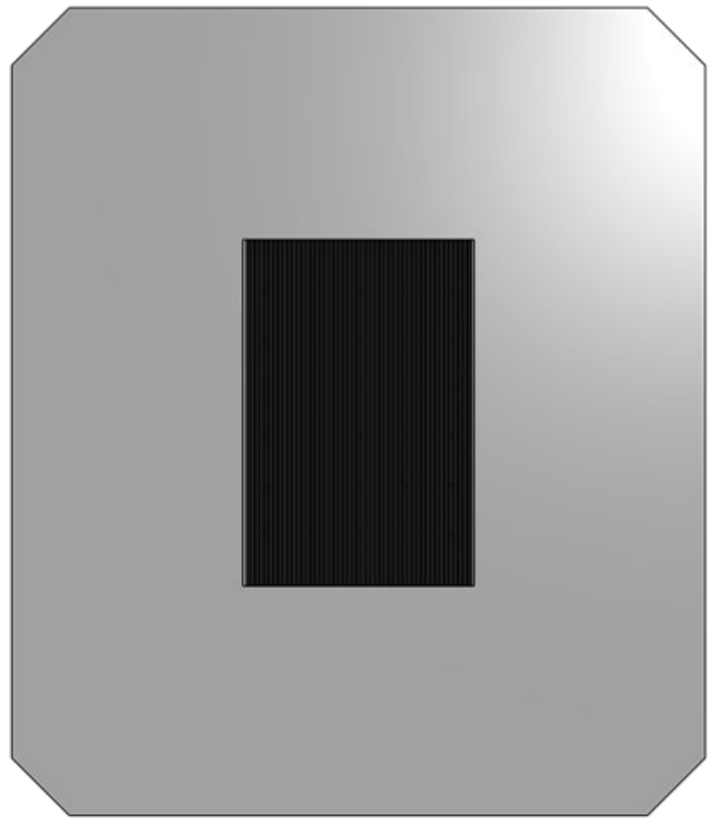

c)

M3 screw

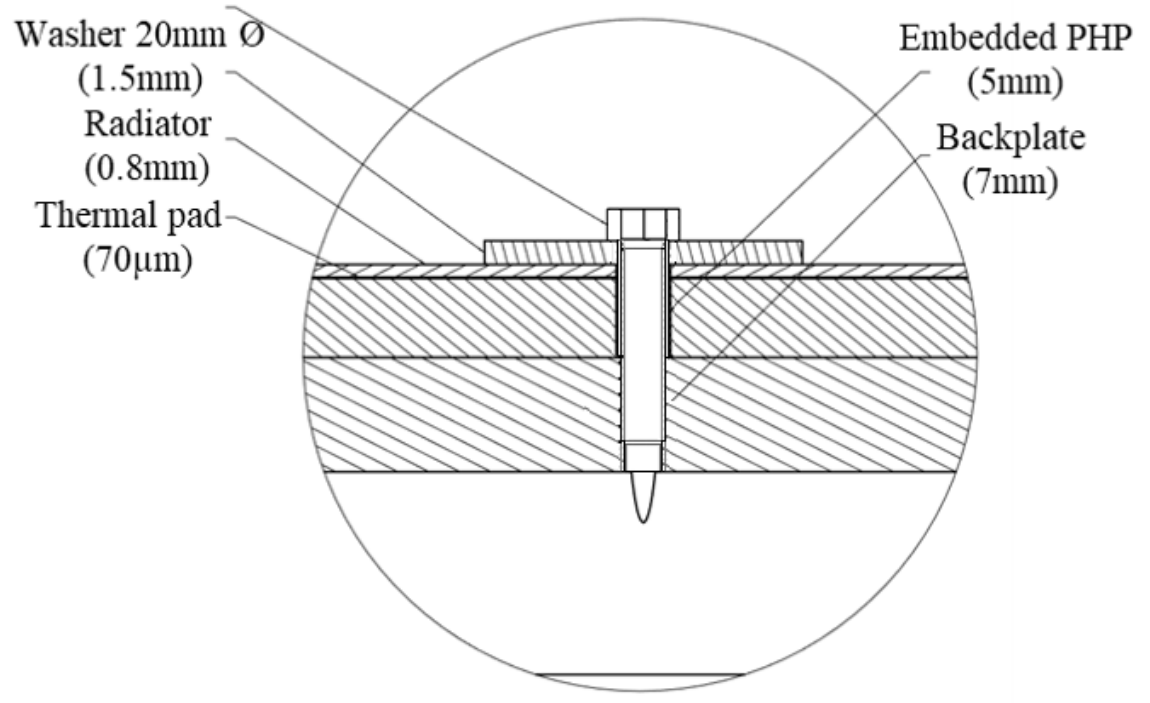

d)

Figure 3: Rendering of the test cell assembly and the radiator. a) Side view of the PHP radiator (Scale 1:4); b) Radiating side: black painted with 30xM3 screw and 30x20mmØ washers (Scale 1:8), with position of the thermocouple on the radiating surface. Thermocouple position (green); c) Inner side: not painted, PHP assembly visible in the centre (Scale 1:8); d) Detail of the cross-section of the test-cell assembly with radiator clamping system.

Since the dimension of the radiating plate is constrained by the size of the thermal vessel contained in the TVC (described in section 2.3), a preliminary thermal simulation of the radiator is needed to verify its heat load capability, operating temperature ranges and thermal gradients. A COMSOL ${ }^{\circledR}$ FEM investigation has been carried out on a simplistic conduction-radiation 
model. The PHP geometry is imported in COMSOL and treated as a conductive medium made of copper. This is a conservative approach since the PHP equivalent thermal conductivities found in the literature are usually higher. A constant heat flux boundary condition is adopted at the evaporator and a black-body radiative heat transfer condition between the radiator plate and the environment is imposed. The input parameters for the FEM model are listed in Table 2. The thermal pad, given the small thickness and high thermal conductivity, it is not considered for the purposes of this investigation.

Table 2 Summary of the input parameters for the FEM modelling of the radiator plate

\begin{tabular}{c|c|l} 
Parameter & Value & \multicolumn{1}{c}{ Description } \\
\hline $\mathrm{P}_{\text {in }}$ & $30-80 \mathrm{~W}$ & $\begin{array}{l}\text { Constant in time, applied to internal surfaces of the PHP } \\
\text { pipework. }\end{array}$ \\
\hline $\mathrm{T}_{\text {sky }}$ & $273 \mathrm{~K}$ & $\begin{array}{l}\text { Sky temperature: temperature of the surface toward which the heat } \\
\text { is radiated }\end{array}$ \\
\hline$\varepsilon$ & $0.9[-]$ & Radiating surface emissivity \\
\hline $\mathrm{k}_{\mathrm{Al}}$ & $205 \mathrm{~W} / \mathrm{m} \mathrm{K}$ & Thermal conductivity Aluminium \\
\hline $\mathrm{k}_{\mathrm{Cu}}$ & $385 \mathrm{~W} / \mathrm{m} \mathrm{K}$ & Thermal conductivity Copper
\end{tabular}

Figure 4 shows the temperature distribution expected across the radiator surface for $\mathrm{T}_{\text {sky }}=213$ $\mathrm{K}$ and an input power of $50 \mathrm{~W}$ (corresponding to a heat flux of $2.4 \cdot 10^{-3} \mathrm{~W} / \mathrm{mm}^{2}$ ). The required temperature condition is expected to be obtained at equilibrium for the sets of input parameters specified. An even lower radiator temperature is expected for lower $\mathrm{T}_{\text {sky }}$, matching the test requirements $(100-273 \mathrm{~K})$.

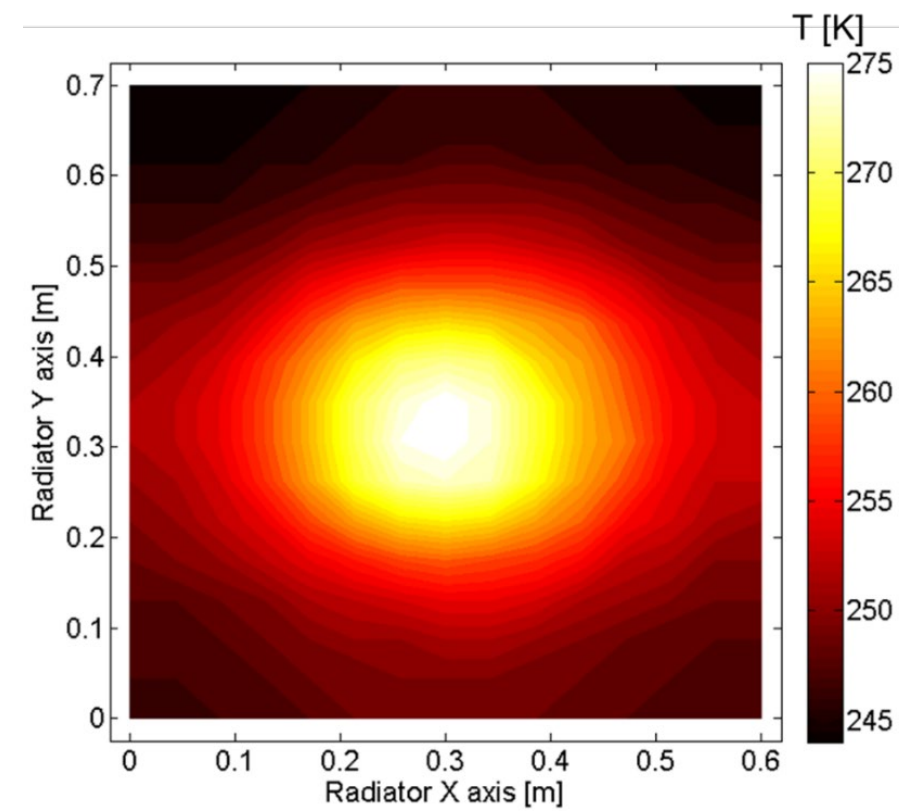

Figure 4: Expected temperature distribution across the radiator surface for test

\subsection{Thermal Vacuum Chamber (TVC) and experiment integration}

The test-cell assembly, composed by the PHP and the radiator, is placed into a thermally controlled vessel which is contained itself inside a cylindrical vacuum chamber (diameter 1.5 $\mathrm{m}$, length $2.5 \mathrm{~m}$ ) as shown in Figure 5. The assembly is placed in horizontal configuration (with the plane of the PHP parallel to ground) since the performances of the same PHP under zero gravity condition are comparable with the test done on ground horizontally [22]. 


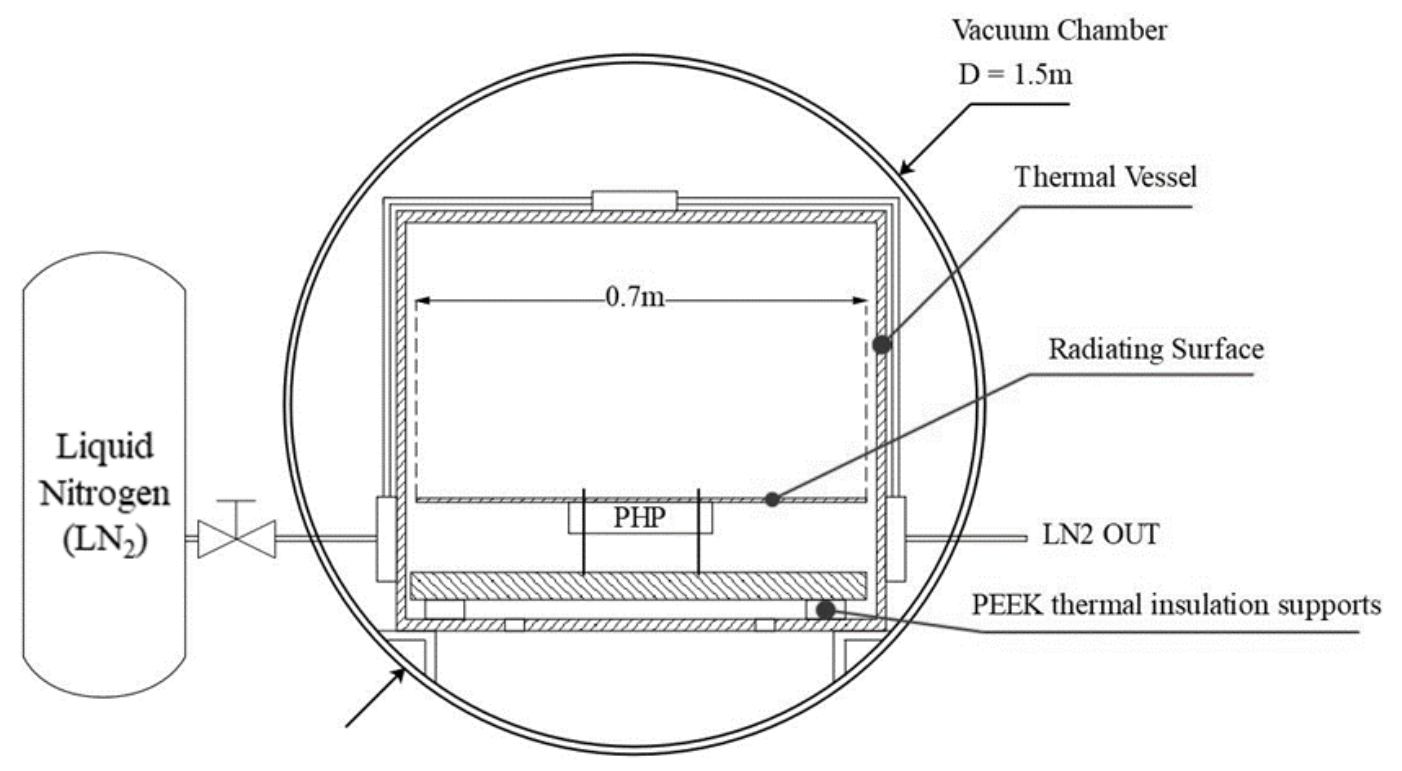

Figure 5: Thermal vacuum chamber (TVC) and position of the thermal vessel with test-cell assembly inside.

The thermal vessel is a box with a dodecagonal base $(\mathrm{R}=900 \mathrm{~mm}, \mathrm{H}=550 \mathrm{~mm})$ made of aluminium which has been used to quickly achieve the required ambient thermal conditions ( $\mathrm{T}_{\text {sky }}$ ). A liquid nitrogen pipeline is connected to each external surface of the vessel (lateral, top and bottom) to cool down the vessel. The lowest temperature achievable for this vessel depends on the fluid used; for liquid nitrogen, it corresponds to $78 \mathrm{~K}$. The internal surfaces of the vessel are black painted to increase the emissivity of the faces viewed by the radiator. A set of thermocouples is placed on the internal surfaces to monitor the temperature of the vessel. Three are distributed on the top face to obtain a more precise value of the temperature. Two holes in the bottom surface allow the suction of the vacuum inside the vessel. The vessel is covered with MLI (Multi-Layer Insulation) blankets to minimize thermal radiation to the outside of the vessel system and then placed inside the vacuum chamber on a support structure.

The required high-vacuum level of $2.6 \cdot 10^{-5}$ mbar is obtained by means of a $70 \mathrm{~W}$ turbomolecular pump (Leybold ${ }^{\mathbb{Q}}, 16 \mathrm{~cm}$ inlet diameter) in line with a rotative roughing pump. The test performed are in accordance with ECSS-Q-ST-70-04C (European Cooperation for Space Standardization) entitled "Space product assurance: Thermal testing for the evaluation of space materials, processes, mechanical parts and assemblies" [27].

\subsection{Experimental procedure and test matrix}

The aim of the experimental campaign is to investigate both the pseudo-steady state reached by the PHP in the TVC and the transient phases that lead to them. The experimental procedure starts with achieving the required vacuum level in the TVC. After the chamber reaches the required pressure $\left(10^{-5} \mathrm{mbar}\right)$, the liquid nitrogen cooling line embedded in the walls of the thermal vessel is activated. Three levels of sky temperature $\left(T_{\text {sky }}\right)$ have been explored (173, $193,213 \mathrm{~K})$. Tsky $_{\text {sk }}$ the temperature of the surfaces involved in the radiative exchange with the radiator plate of the test cell and is obtained with a $-5 /+2 \mathrm{~K}$ accuracy. Preliminary tests showed that no start-up is reached below $40 \mathrm{~W}$ so, when the thermal vessel reaches the desired $\mathrm{T}_{\text {sky }}$, a pre-heating phase of the PHP ( $40 \mathrm{~W}$ for $60 \mathrm{~min}$ ) is performed to bring the device closer to the 
start-up condition. The power input profiles chosen for the campaign (shown in Table 4) follow two types of logic:

- A standard cycle, structured in a three-step increase of power input from 50W up to $80 \mathrm{~W}$, followed by a three-step power decrease. This cycle allows to explore the startup phase and thermal hysteresis phenomena for equal power levels;

- A decreasing cycle, where a six-step decreasing of power input from $80 \mathrm{~W}$ to $30 \mathrm{~W}$ is explored. This cycle will explore blockage phenomena due to temperature-induced increase of the viscous stress.

The tests have all been conducted in horizontal orientation because for a planar capillary device on ground this is the closest condition to the microgravity [20].

Table 3: Experimental matrix.

\begin{tabular}{|c|c|c|c|c|c|c|c|c|}
\hline Test & $\mathrm{T}_{\text {sky }}[\mathrm{K}]$ & \multicolumn{7}{|c|}{ Power [W] } \\
\hline 1 & 213 & \multirow{6}{*}{$\begin{array}{c}\text { 40W Pre- } \\
\text { heating } \\
\text { phase }\end{array}$} & 50 & 70 & 80 & 70 & 50 & 30 \\
\hline 2 & 213 & & 80 & 70 & 60 & 50 & 40 & 30 \\
\hline 3 & 193 & & 50 & 70 & 80 & 70 & 50 & 30 \\
\hline 4 & 193 & & 80 & 70 & 60 & 50 & 40 & 30 \\
\hline 5 & 173 & & 50 & 70 & 80 & 70 & 50 & 30 \\
\hline 6 & 173 & & 80 & 70 & 60 & 50 & 40 & 30 \\
\hline
\end{tabular}

Evaporator wall-to-fluid heat flux: $3.51 \mathrm{~W} / \mathrm{cm}^{2}$ at $30 \mathrm{~W} ; 9.38 \mathrm{~W} / \mathrm{cm}^{2}$ at $80 \mathrm{~W}$

\section{Results and Discussion}

The results are presented in terms of pressure and temperature temporal evolution, as recorded during the campaign and in terms of equivalent thermal resistance, in order to characterise the thermal performance. A qualitative analysis has been conducted with a focus on global trends and different operational modes of the PHP. Attention has been drawn to the conditions that lead to the device blockage when both $\mathrm{T}_{\text {sky }}$ and power input decrease. The pressure signal is exploited to identify the PHP operating phases and to define the dominant oscillation frequencies. The fluid inside the PHP is considered confined and a dominant slug-plug is expected in the entire range of the investigation. Indeed for FC-72 in static conditions without any heat load, the internal diameter size of $1.1 \mathrm{~mm}$ is always below the critical diameter according to Kew and Cornwell [28] as shown in Figure 6. 


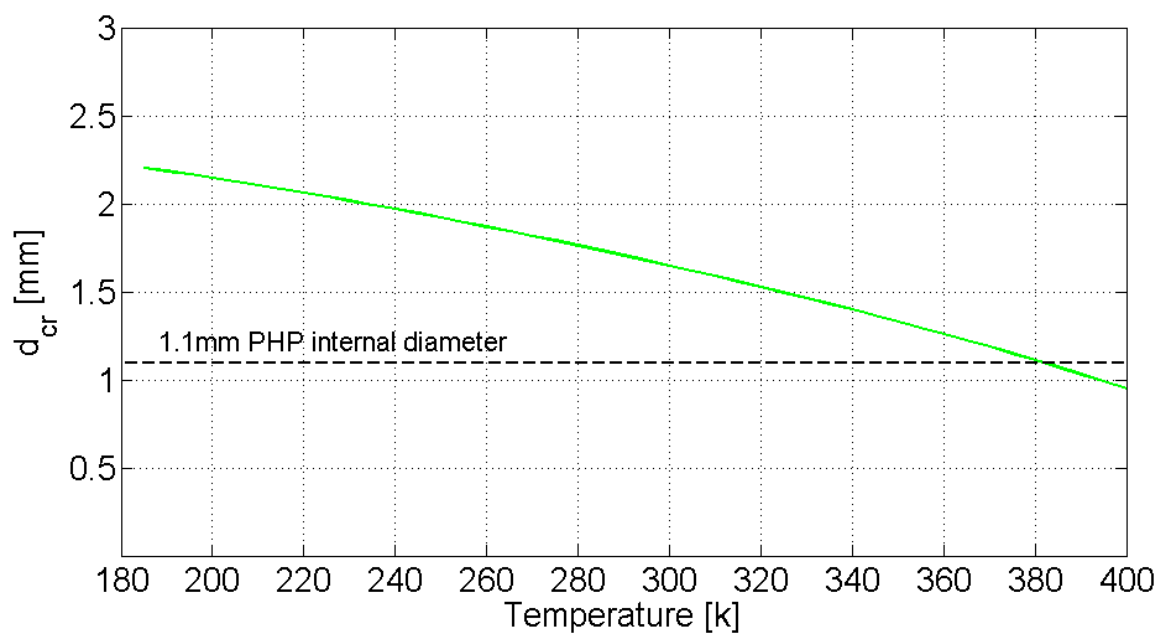

Figure 6: Critical diameter for FC-72 in an extended temperature range. Black dashed line refers to the internal diameter of the present work.

\subsection{Operation and regimes}

The phase prior to the start-up, No Operation (NO) phase, is characterised by a flat trend of pressure (no fluid motion). The start-up (SU) phase is defined as the period between the powerup and the significant drop in temperature that marks the full activation; this cannot be achieved at all power inputs: a minimum activation power, depending on the geometrical and thermodynamic parameters has to be provided. During this phase, the pressure oscillations are generally low in amplitude, alternated with unpredictable spikes. This phase terminates with the reaching of pressure oscillations more regular and contained in a rather predictable range; same for the temperature, which oscillates across a stable temperature average. The condenser temperature keeps a stable and flat trend. This marks the activation of the PHP and the beginning of a Stable Operation phase (SO). When the system reaches a stable operation, the fluid temperature at the evaporator drops significantly, reducing the temperature gradient across the PHP channels. A crisis of the PHP is recognizable at the end of each test cycle since the pressure oscillation shows an intermittent trend (start-stop), slowly damps out and the flow motion finally stops; this phase is defined as the blockage (B) of the PHP. Figure 7 shows the global temperature trends during a standard cycle, identifying the operative phases previously described.

For each case listed in Table 4, the temperature dataset acquired is shown in Figure 8. Each plot corresponds to one test case, performed at a specific $\mathrm{T}_{\text {sky. }}$. Each test lasts nine hours and each input power level is kept for at least one hour to ensure the reaching of the pseudo steady state. One of the aims of the experimental campaign was to investigate the lower limit of the power input at which the fluid oscillation stops for a given constant $T_{\text {sky }}$. 


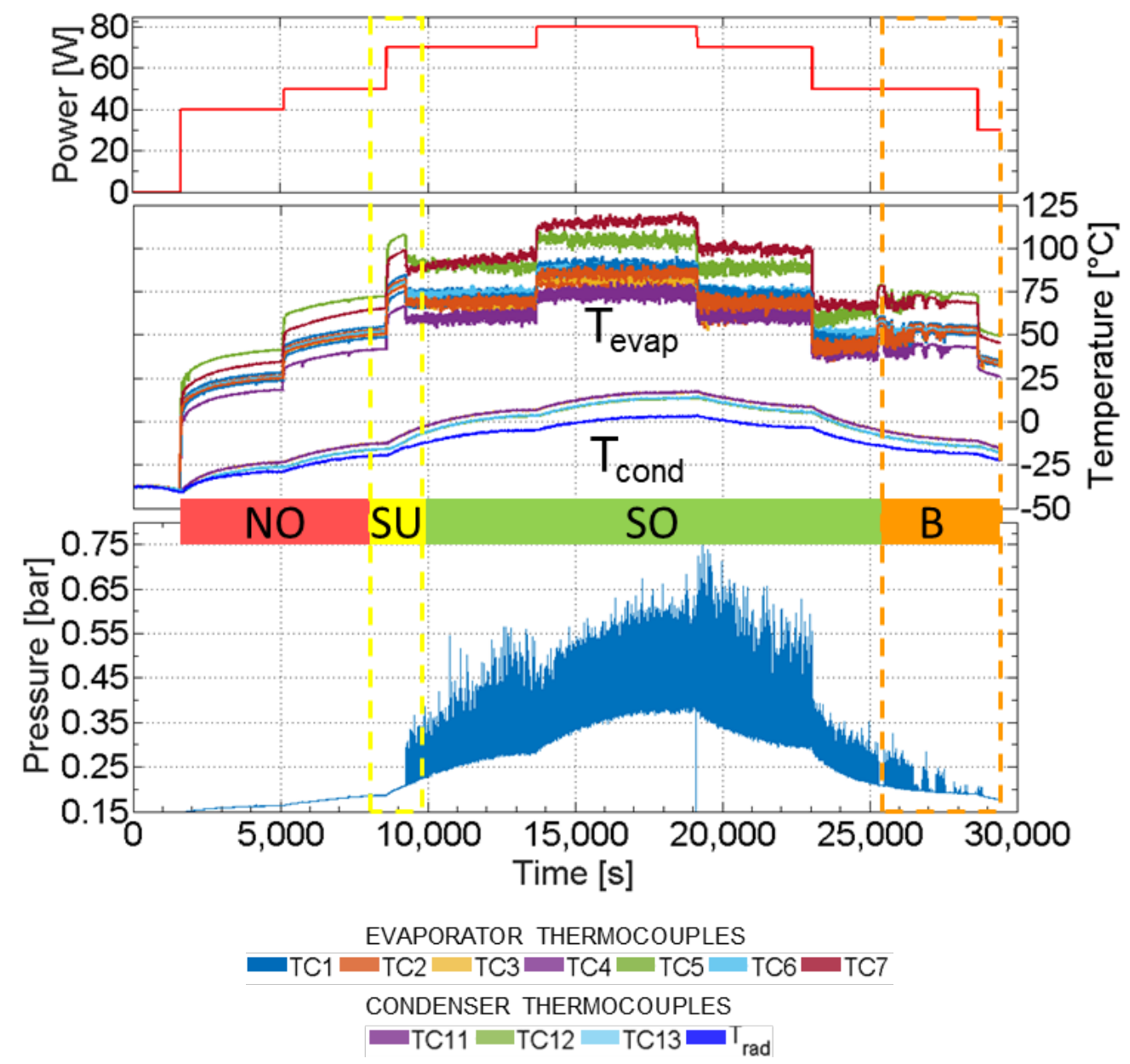

Figure 7: Synoptic graphs of Power input, Temperature (both evaporator and condenser) and pressure with main operating phases $\left(T_{\text {sky }}=193 \mathrm{~K}\right)$. Identification of the operational modes; attention is drawn to the Sturt-Up phase (yellow dashed box) and to the Blockage phase (orange dashed box).

As shown in Figure 8, the temperature of the TVC has a clear influence on the start-up. The PHP needs higher power input to reach the activation at lower $\mathrm{T}_{\text {sky. }}$ The operating regimes identified for each test cycle are reported in Table 5 . For the lowest Tsky $=173 \mathrm{~K}, 80 \mathrm{~W}$ are required to start the PHP. Therefore, the fluid must be provided with a higher power input to achieve the initial energy required to initiate the oscillation. For the lowest Tsky $=173 \mathrm{~K}, 80 \mathrm{~W}$ are required to start the PHP up.

The following main observation were noted:

- No activation is recorded during the pre-heating phase at $40 \mathrm{~W}\left(4.69 \mathrm{~W} / \mathrm{cm}^{2}\right)$ for all $\mathrm{T}_{\text {sky}}$;

- Start-Up occurs at higher input power levels as $\mathrm{T}_{\text {sky }}$ decreases;

- Decreasing $\mathrm{T}_{\text {sky }}$ causes the stop of the oscillations at higher power inputs compared to higher $\mathrm{T}_{\text {sky }}$;

- Thermal inertia and dynamic inertial phenomena allow the fluid to keep on oscillating at lower power input during the power step-down phase of a standard cycle if compared to the power step-up phase (PHP hysteresis).

The increasing of the minimum power required for the Start-Up is related to the equilibrium conditions of the PHP. For a lower value of $\mathrm{T}_{\text {sky }}$ a lower temperature (and consequently pressure) is expected inside the PHP channels at equilibrium. 
a) Test 1: Standard cycle $T_{\text {sky }}=213 \mathrm{~K}$

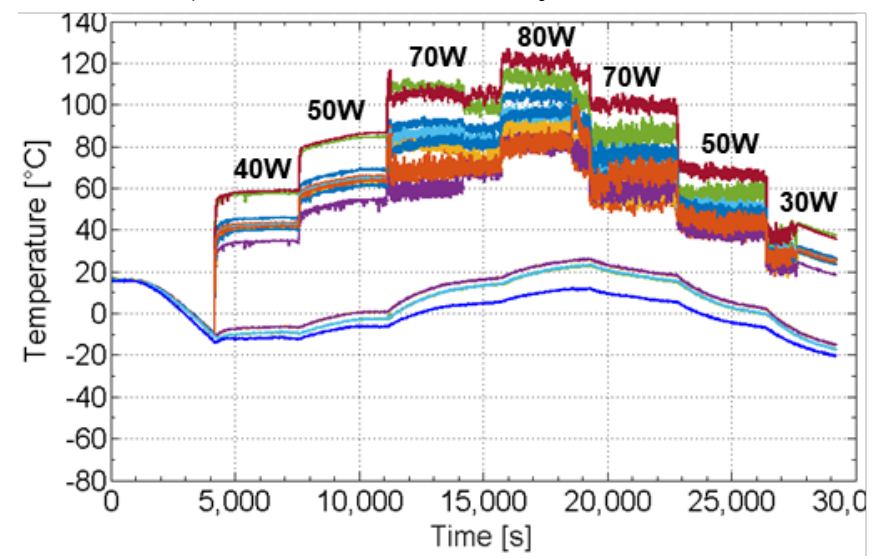

c) Test 3: Standard cycle $T_{\text {sky }}=193 \mathrm{~K}$

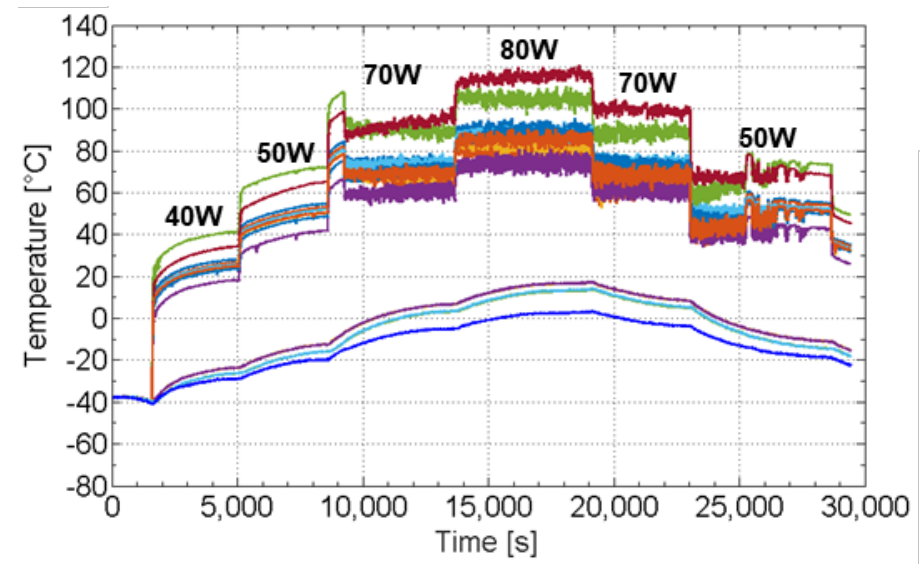

e) Test nr.5: Standard cycle $T_{\text {sky }}=173 \mathrm{~K}$

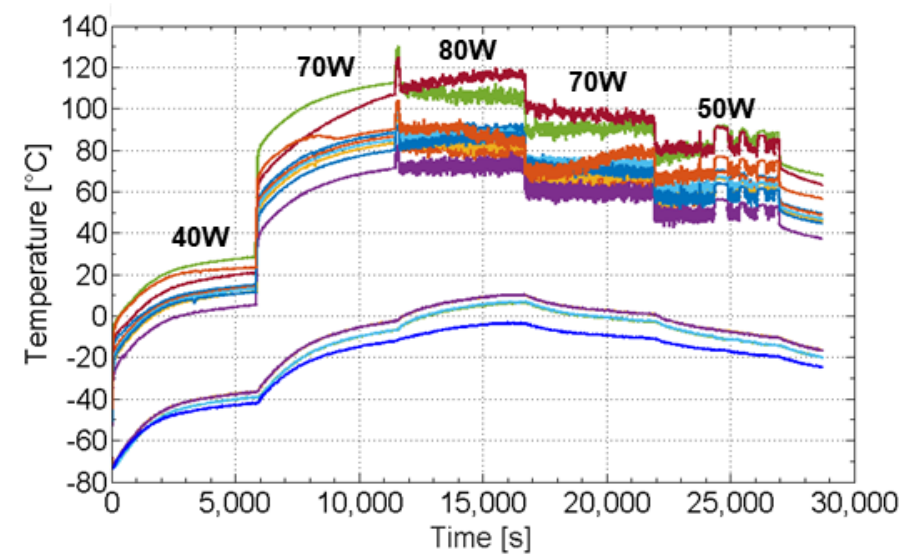

b) Test 2: Decreasing cycle $\mathrm{T}_{\text {sky }}=213 \mathrm{~K}$

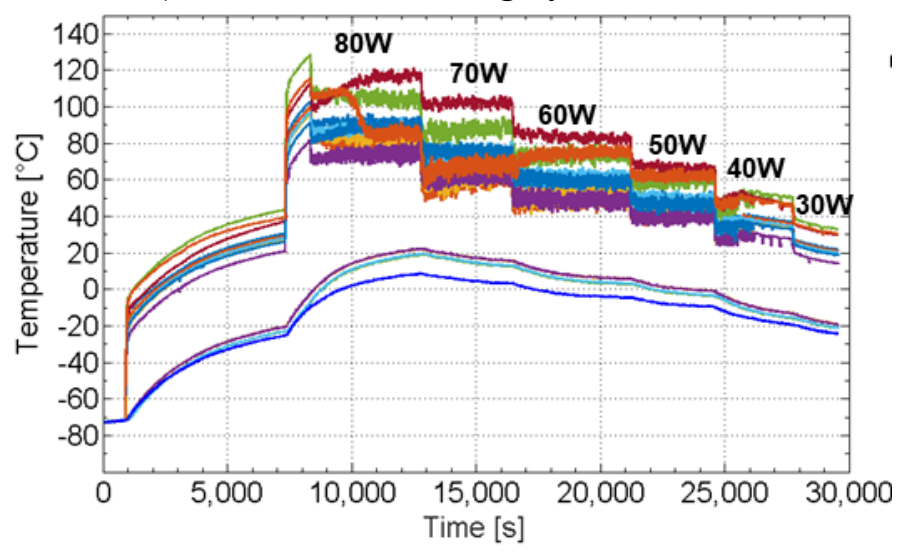

d) Test 4: Decreasing cycle $T_{\text {sky }}=193 \mathrm{~K}$

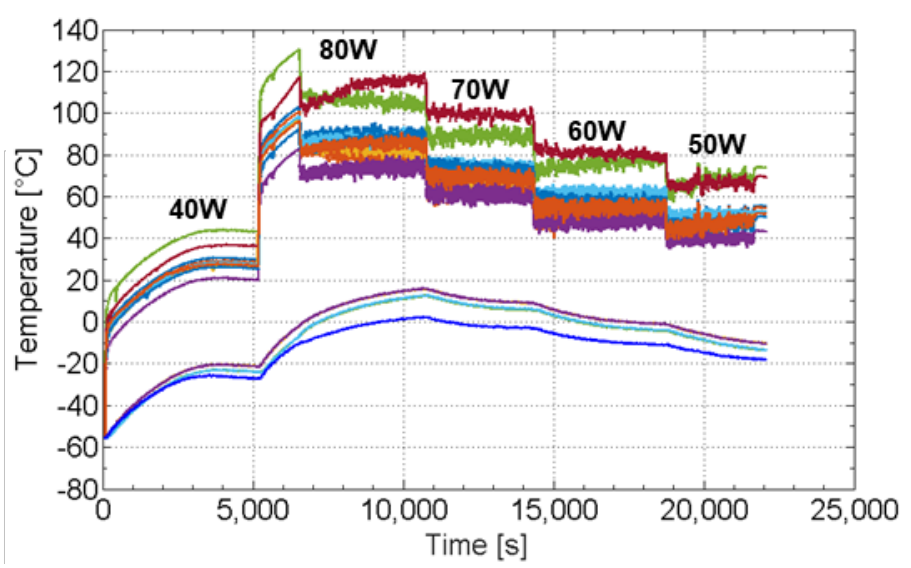

f) Test nr.6: Decreasing cycle $\mathrm{T}_{\text {sky }}=173 \mathrm{~K}$

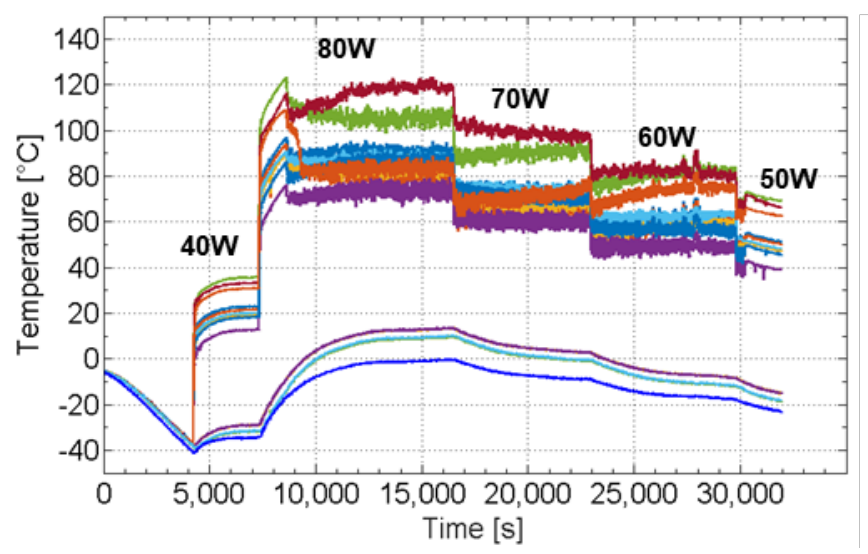

EVAPORATOR THERMOCOUPLES

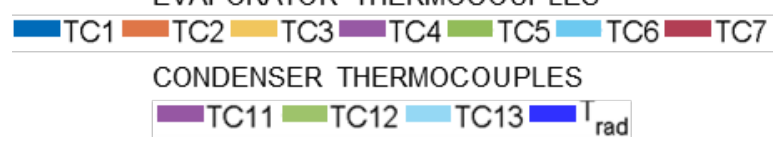

Figure 8: Global trend of evaporator temperatures, condenser temperature, radiator surface temperature and power input for each test case listed in Table 4

Therefore, the fluid must be provided with a higher power input to overcome the initial energy required to initiate the oscillation. For the lowest $\mathrm{T}_{\text {sky }}=173 \mathrm{~K}, 80 \mathrm{~W}$ are required to start the PHP. 
Table 4: Regime detection matrix for horizontal operation under different $T_{\text {sky }}$ and heating cycle described in Table 4. NO = No Operation; $\mathrm{SU}=\mathrm{Start}-\mathrm{Up}$; $\mathrm{SO}=$ Stable Operation; $\mathrm{B}=$ Blockage.

\begin{tabular}{|c|c|c|c|c|c|c|c|c|c|c|}
\hline & & \multicolumn{9}{|c|}{ Power [W] } \\
\hline $\begin{array}{c}\text { Test } \\
\text { nr. }\end{array}$ & $\begin{array}{l}\mathrm{T}_{\text {sky }} \\
{[\mathrm{K}]}\end{array}$ & $\begin{array}{c}\text { Pre- } \\
\text { heating } \\
40\end{array}$ & 50 & 70 & 80 & 70 & 60 & 50 & 40 & 30 \\
\hline 1 & \multirow{2}{*}{213} & \multirow{6}{*}{ NO } & NO & $\mathrm{SU} / \mathrm{SO}$ & $\mathrm{SO}$ & $\mathrm{SO}$ & $\mathrm{N} / \mathrm{A}$ & SO & $\mathrm{N} / \mathrm{A}$ & B \\
\hline 2 & & & $\mathrm{~N} / \mathrm{A}$ & N/A & $\mathrm{SU} / \mathrm{SO}$ & $\mathrm{SO}$ & SO & SO & B & $\mathrm{NO}$ \\
\hline 3 & \multirow{2}{*}{193} & & $\mathrm{NO}$ & $\mathrm{SU} / \mathrm{SO}$ & $\mathrm{SO}$ & $\mathrm{SO}$ & $\mathrm{N} / \mathrm{A}$ & $\mathrm{SO} / \mathrm{B}$ & $\mathrm{N} / \mathrm{A}$ & $\mathrm{NO}$ \\
\hline 4 & & & $\mathrm{~N} / \mathrm{A}$ & N/A & $\mathrm{SU} / \mathrm{SO}$ & $\mathrm{SO}$ & SO & $\mathrm{SO} / \mathrm{B}$ & $\mathrm{NO}$ & $\mathrm{NO}$ \\
\hline 5 & \multirow{2}{*}{173} & & $\mathrm{NO}$ & NO & $\mathrm{SU} / \mathrm{SO}$ & $\mathrm{SO}$ & $\mathrm{N} / \mathrm{A}$ & $\mathrm{SO} / \mathrm{B}$ & $\mathrm{N} / \mathrm{A}$ & $\mathrm{NO}$ \\
\hline 6 & & & N/A & N/A & $\mathrm{SU} / \mathrm{SO}$ & $\mathrm{SO}$ & SO & B & $\mathrm{NO}$ & $\mathrm{NO}$ \\
\hline
\end{tabular}

\subsection{Transient phases: the start-up and the blockage phenomenon}

The transient phases (start-up and blockage) are clearly and deeply affected by the environment temperature reduction. A decrease of the cold source temperature $\left(\mathrm{T}_{\mathrm{sky}}\right)$ results in a lower temperature of the condenser zone. This means that also the fluid mean temperature in the condenser sets to a lower level and the liquid dynamic viscosity increases considerably while the Clausius-Clapeyron ratio $d P /\left.d T\right|_{\text {sat }}$ reduces. The fluid motion in the transient phases is then affected by both fluid-dynamic and thermodynamic factors.

1) Thermodynamic: The role of thermodynamic non-equilibrium is at the very basis of the PHP operation. The existence of several degrees of superheating in the vapor phase has been experimentally proven by many authors in the literature [19], [29], [30] but its effect on the fluid motion (i.e. spring or damping action) is still a debated issue in the literature. Nikolayev et al. [31] proposed a consistent theoretical modelling of such effect by proposing a merit number based on the Clausius Clapeyron ratio coupled with the ideal gas equation of state and the energy balance on a single pure vapor bubble. From their results it seems that the thermodynamic spring action increases at lower temperatures for all the fluids and that, among them, the FC-72 is one of the worst in terms of spring action. Nikolayev et al. [31] declare that the fluid merit is certainly linked to the fluid dynamic aspects too (fluid viscosity) but they have not been accounted for in the analysis. Furthermore, their outcomes still need to be validated by means of experimental data.

2) Fluid-dynamic: a lower fluid temperature results in higher pressure losses due to the increase of the dynamic viscosity. The consequent increase of the viscous losses acts as a barrier during the start-up phase and as a damping factor on the plugs-slugs oscillation during the blockage phase. The latter is defined here as viscous drag blockage: if the heat input level decreases, the driving pressure difference, induced by the vaporisation and condensation processes, is not able to overcome the viscous losses, the fluid motion becomes first intermittent and then stops.

Figure 9a shows the fluid dynamic viscosity trend against the fluid temperature, while Figure $9 \mathrm{~b}$ shows the Clausius-Clapeyron ratio against the fluid temperature. The red and blue dashed frames represent the fluid temperature ranges at the evaporator and condenser respectively, 
recorded during the blockage phase. These temperatures have been extrapolated from the average pressure signals assuming saturated conditions for sake of simplicity.

a)

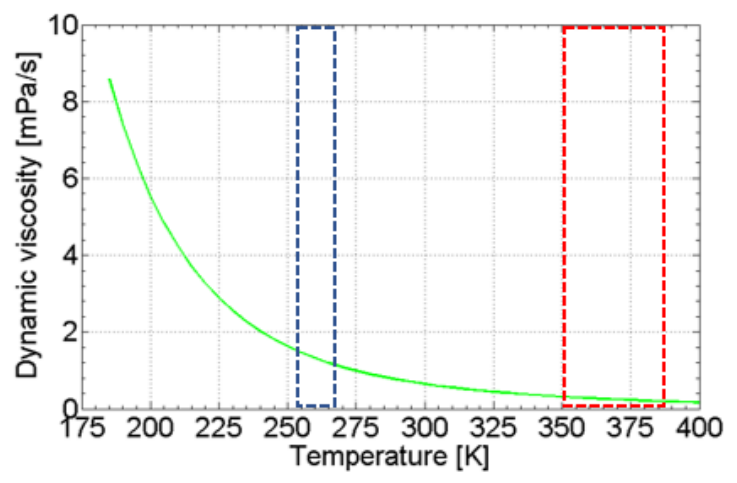

b)

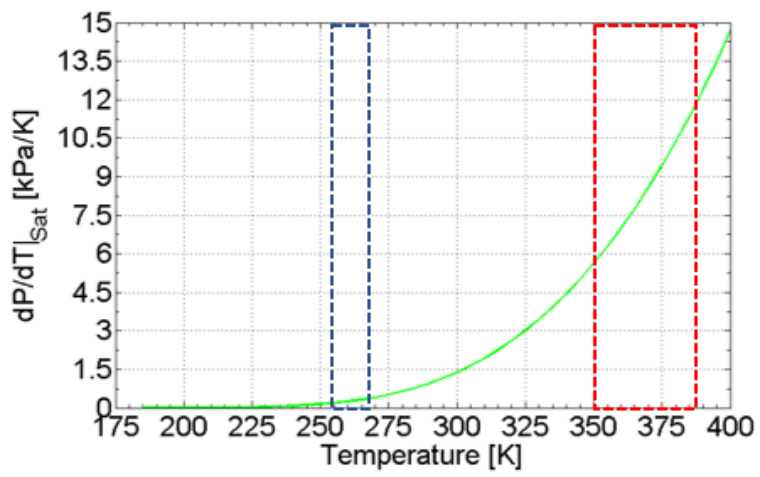

Figure 9: a) Dynamic viscosity and b) Clausius-Clapeyron ratio for FC-72 against the temperature range of interest.

Being at lower temperatures with respect to the evaporator, the condenser zone is more affected by the steeper increase in the dynamic viscosity against temperature (blue box in Fig. 13a). Furthermore, since the condenser zone covers a very wide surface with respect to the evaporator, the viscous blockage effect plays a major role: the oscillation damping in the condenser reflects at the evaporator level too: if the fluid coming from the condenser is not able to return to the evaporator, partial dry-out zones may appear, causing initially a start-and-stop like behaviour and after that a further damping of the fluid motion. Such self-exciting combination leads from a partial dry-out to a complete stop of the fluid motion and the full thermal crisis of the system.

A better insight into the dynamic of the blockages can be obtained thanks to the pressure signal analysis. The blockage is reached when the pressure is showing a constant flat trend. As shown in Figure 10, prior to a complete blockage of the PHP, a pre-blockage phase is visible. During this phase, a continuous damping in the pressure amplitude oscillation takes place. The pressure trends can show both sudden stopover or temporary flattening of the pressure oscillation alternated with reactivation of the oscillation as a prelude to the definitive blockage. This gradual behaviour is justified by the interconnection between pipes of the PHP and the different local distribution of phases; this can cause a blockage in some of the pipes but not in other. The fluid in the still-active pipes forces the fluid in adjacent blocked pipes to keep on moving until the number of active pipes is not enough to sustain a circulation.

\subsection{Dominant frequency during stable operation}

In order to quantify the effect of heat input level and of the environment temperature $\mathrm{T}_{\text {sky }}$ (and consequently $\left.\mathrm{T}_{\text {fluid }}\right)$ on the oscillation, the pressure signal fluctuations are analysed through a time-frequency technique based on the continuous Wavelet Transform (WT). The Wavelet Transform is preferred to Short Time Fourier Transform (STFT) because it allows to dynamically increase the frequency resolution at lower frequency values, whereas to increase time resolution at higher frequency values (in STFT the frequency resolution is fixed). Moreover, compared to classical Fourier spectra, the wavelet-based procedure are well defined from the mathematical point of view and obtains smoother spectra. 
a) Test 1: Standard cycle $T_{\text {sky }}=213 \mathrm{~K}$,

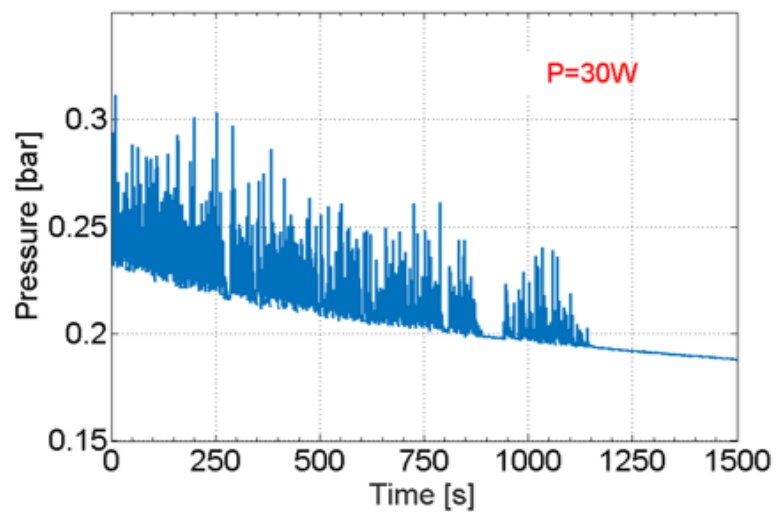

c) Test 3: Standard cycle $\mathrm{T}_{\text {sky }}=193 \mathrm{~K}$

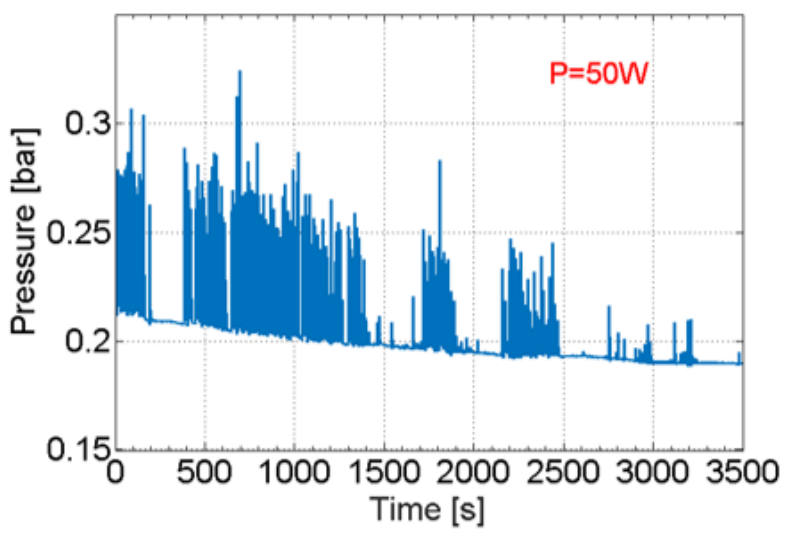

e) Test 5: Standard cycle $T_{\text {sky }}=173 \mathrm{~K}$

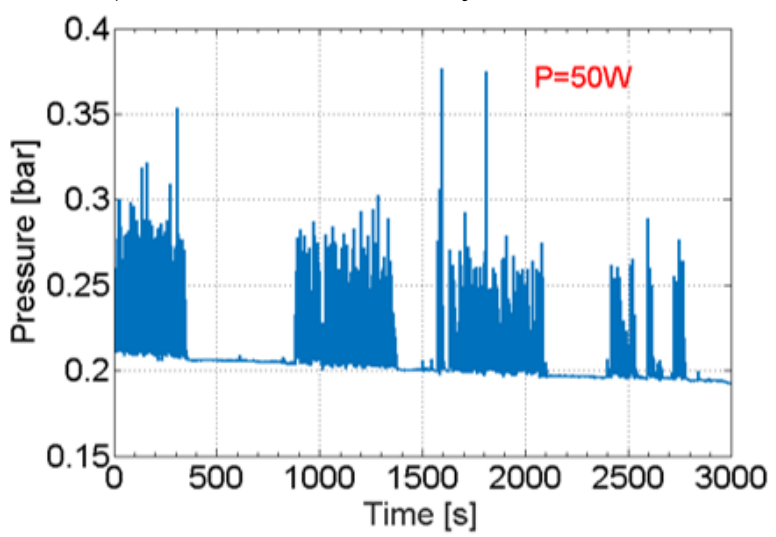

b) Test 2: Decreasing cycle $T_{\text {sky }}=213 \mathrm{~K}$

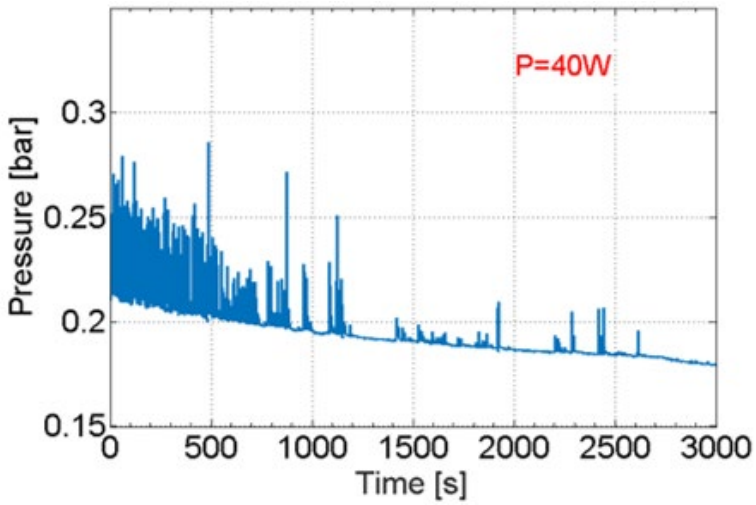

d) Test 4: decreasing cycle $T_{\text {sky }}=193 \mathrm{~K}$

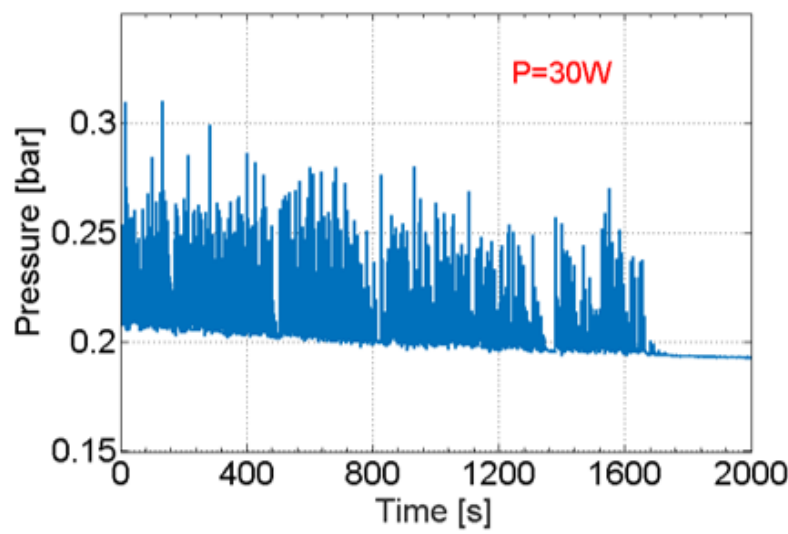

f) Test 6: decreasing cycle $\mathrm{T}_{\text {sky }}=173 \mathrm{~K}$

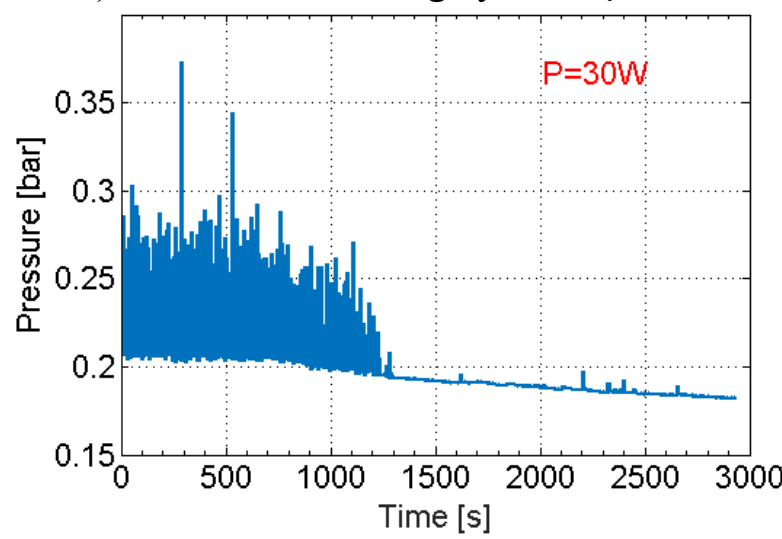

Figure 10: Pressure trend during the pre-blockage and blockage phase. The power level indicated in red is the one at which the blockage has been recorded.

For processing the signals, a wavelet tool previously developed and successfully applied by Perna et al. [32], has been used. In the same work, the definition of the dominant frequency $\bar{f}_{D}$ is provided and described as the frequency corresponding to the absolute maximum of the power spectrum $P_{W t}(f)$. The Wavelet analysis is here performed on the fluid pressure signal $P_{f}$ at the condenser and on a frequency range from 0.01 to $4 \mathrm{~Hz}$. The following parameters have been imposed for this investigation: the acquisition frequency of the pressure signal $f_{A c}=100$ $\mathrm{Hz}$ and the number of samples $N_{W t}=65536$ are chosen for an analysis time $t_{A n}=655.36 \mathrm{~s}$. The results of the Wavelet analysis are reported in the form of time-frequency energy maps, also called "scalograms" and wavelet power spectra $P_{W x}$. In the scalogram, the colour represents the 
energy value at the given time and frequency. The related spectrum will be used for the identification of the dominant frequencies. An example of Wavelet Scalogram and Power Spectrum of the pressure signal for case 1, is performed for each power level before the blockage, is shown in Figure 11.

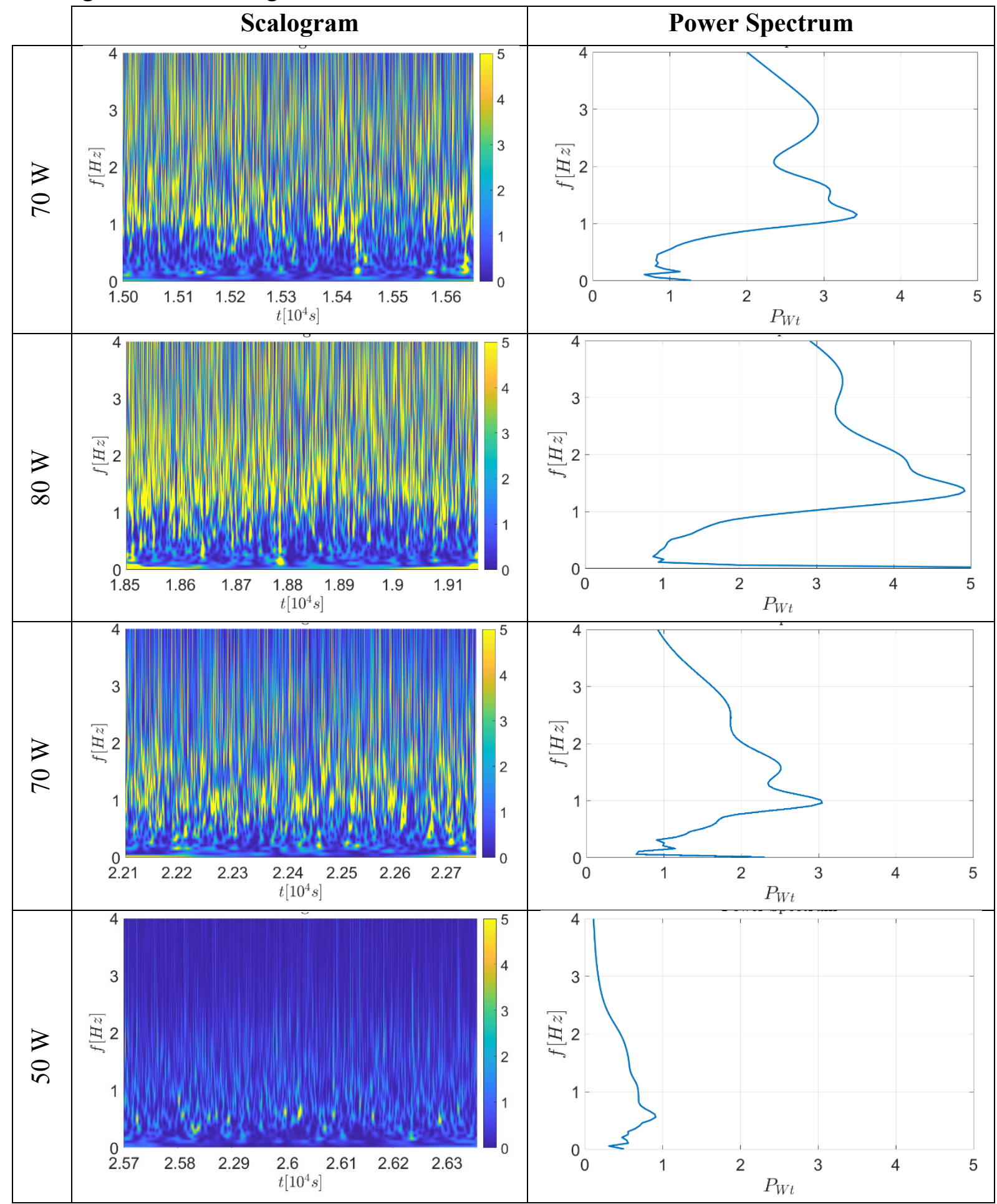

Figure 11: Scalogram and power spectrum for the power inputs of Test Case 1 analysed before the blockage $\left(T_{\text {sky }}=213 \mathrm{~K}\right)$

Scalogram and power spectrum for all the other cases in Table 4 provide similar results and for this reason they have been shifted to Appendix B. The dominant frequency characterising the oscillation of the embedded PHP during the TVC tests are identified and listed in Table 6. 
Table 5: Dominant frequencies for the three $T_{\text {sky }}$ investigated at varying power input.

\begin{tabular}{|c|c|c|c|}
\hline $\mathrm{T}_{\text {sky }}[\mathrm{K}]$ & $\mathrm{Q}[\mathrm{W}]$ & $\bar{f}_{D}[\mathrm{~Hz}]$ & $\sigma_{f_{D}}[\mathrm{~Hz}]$ \\
\hline \multirow{4}{*}{213} & 50 & 0.53 & 0.04 \\
& 60 & 0.71 & - \\
& 70 & 1.04 & 0.1 \\
& 80 & 1.34 & 0.04 \\
\hline \multirow{3}{*}{193} & 60 & 0.56 & - \\
& 70 & 0.98 & 0.2 \\
& 80 & 1.16 & - \\
\hline \multirow{3}{*}{173} & 60 & 0.51 & - \\
& 70 & 0.66 & - \\
& 80 & 1.4 & 0.04 \\
\hline
\end{tabular}

Where $\sigma_{f_{D}}$ represents the uncertainty in the frequency domain. For a better understanding and comparison of the different trends, the dominant frequencies are plotted over the heat input levels using different colours for the different environment temperatures in Figure 12.

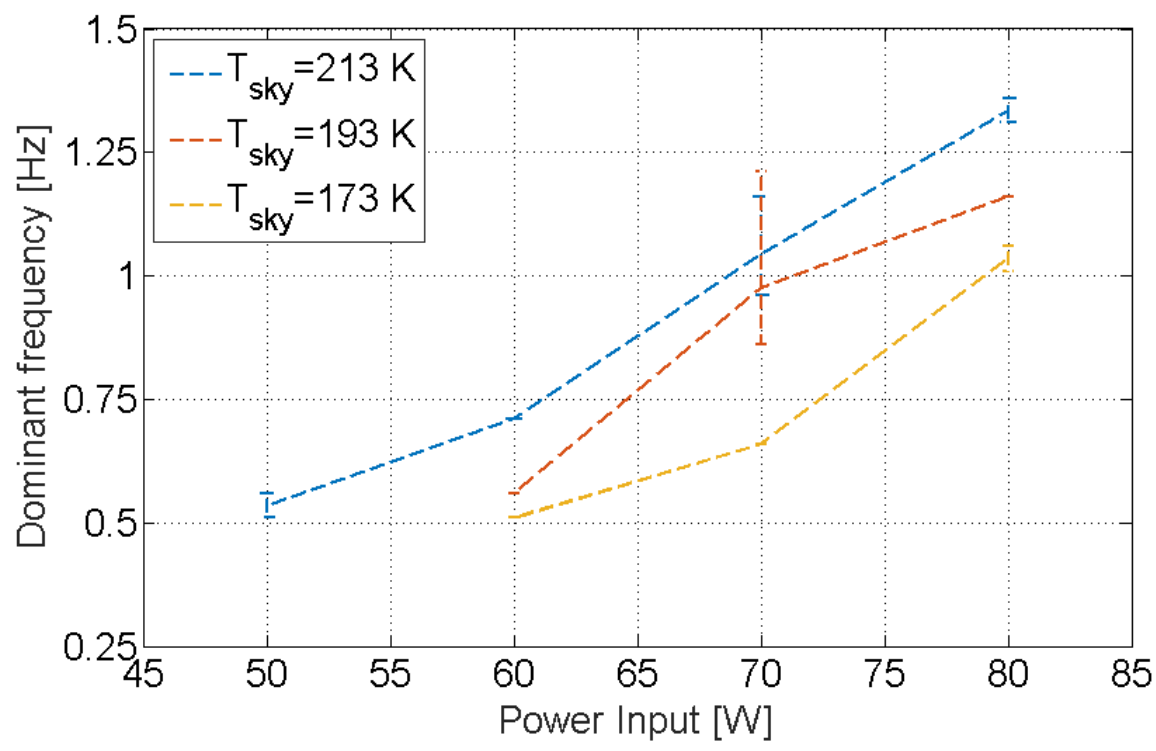

Figure 12: Dominant oscillation frequency trends with power input and standard deviation bars.

It can be noticed that the oscillation frequency is always increasing with the power input applied to the evaporator, while it sets to lower values as the environment temperature $T_{\text {sky }}$ decreases. In order to understand the effect of the environment temperature on the thermal performance of the radiative PHP, the equivalent thermal resistance $R_{e q}$ is calculated for each power input and each $T_{\text {sky. }}$ It is defined as the difference between the mean temperature value between the PHP evaporator and condenser:

$$
R_{e q}=\frac{\bar{T}_{e v}-\bar{T}_{c o}}{\dot{Q}}
$$

The resulting thermal resistance, evaluated for the only decreasing power test cycles, are reported in Figure 13. As expected, the PHP works more efficiently for higher input power. A trend that can be highlighted is the increase of the thermal resistance for lower values of $T_{\text {sky }}$. 
This reflects the role of increasing viscous losses coupled with a reduced driving $\Delta \mathrm{P}$ at the ends of each branch of the PHP on the thermal performance of the device.

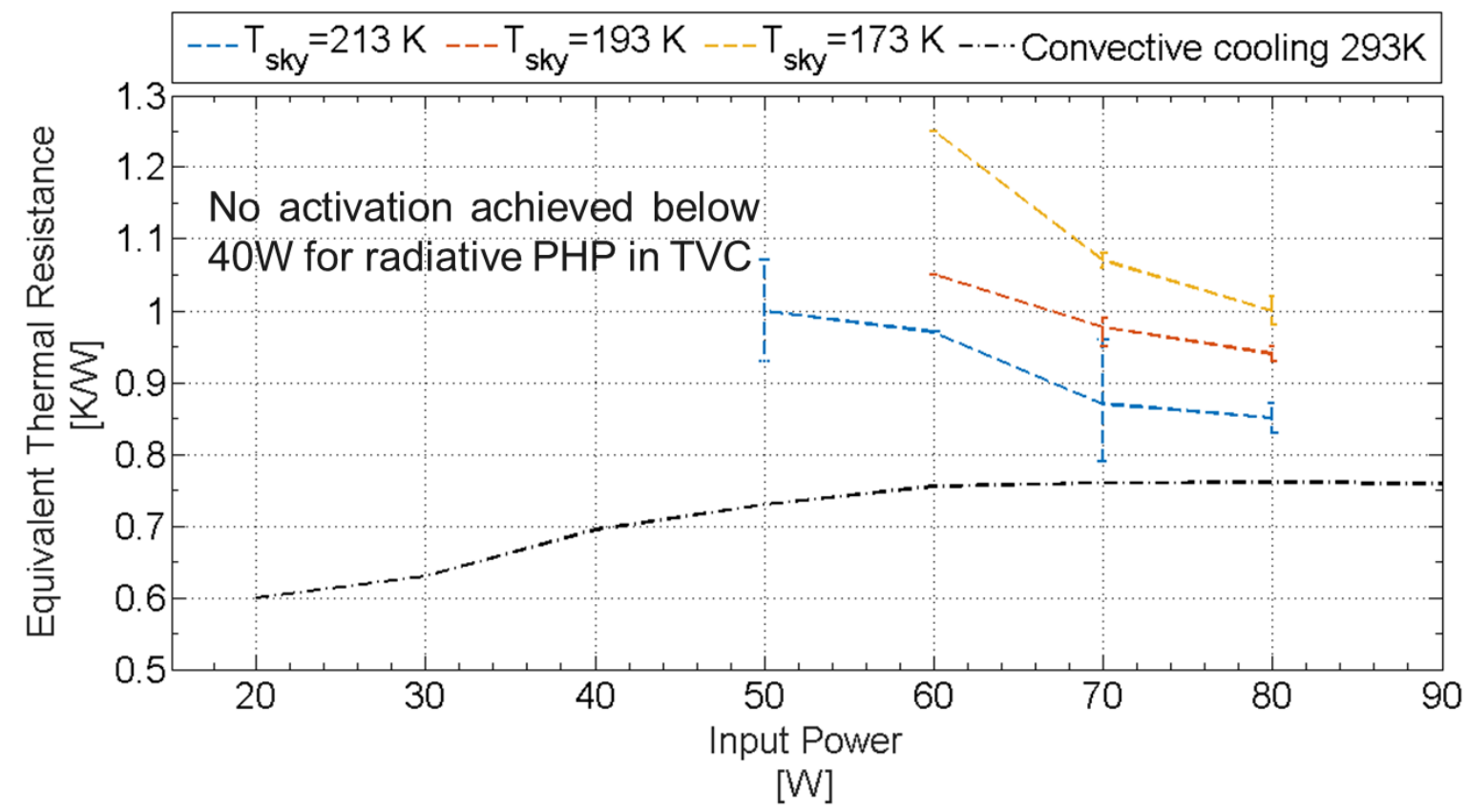

Figure 13: Effect of power input on the equivalent thermal resistance for the three $T_{\text {sky }}$ tested and comparison with [22] (dots and dashes black line).

For the sake of comparison, the black line refers to the experimental data collected in a previous work [22] where the same PHP test cell without the radiator, was tested in microgravity condition, horizontal operation, and cooled by means of forced convection (the air temperature was kept at $293 \mathrm{~K}$, heat transfer coefficient estimated: $30 \mathrm{~W} / \mathrm{mK}$ ). It seems that the radiative configuration mostly affects the PHP performance due to the lower operative temperatures needed to obtain a reasonable heat rejection, rather than due to the heat transfer mode itself. Indeed, the performance degradation of the blue line (radiative heat transfer with $T_{s k y}=213 \mathrm{~K}$ ) with respect to the black one (convective heat transfer with $T_{\text {air }}=293 \mathrm{~K}$ ) is comparable to the performance decrease between the blue and red lines. The decrease in the environment temperature mostly affects the start-up heat input ranges, confirming the fact that higher heat inputs are needed for starting the system up at lower operating temperatures.

It can be useful to understand the effect of the dominant frequency on the thermal performance of the device. Figure 14 shows the equivalent thermal resistance as a function of the dominant frequency. It is clear how higher oscillation frequencies are characteristic of lower equivalent thermal resistances; this can be explained with a better heat transfer process at the evaporator, which is constantly supplied by "fresh" fluid coming from the condenser zone. For the design of future PHPs that will operate in LEO or deep space, this confirms the importance of testing of a PHP in an environment that simulate space conditions; the risk is overestimating the performances in terms of heat transfer efficiency and operating range of the device. 


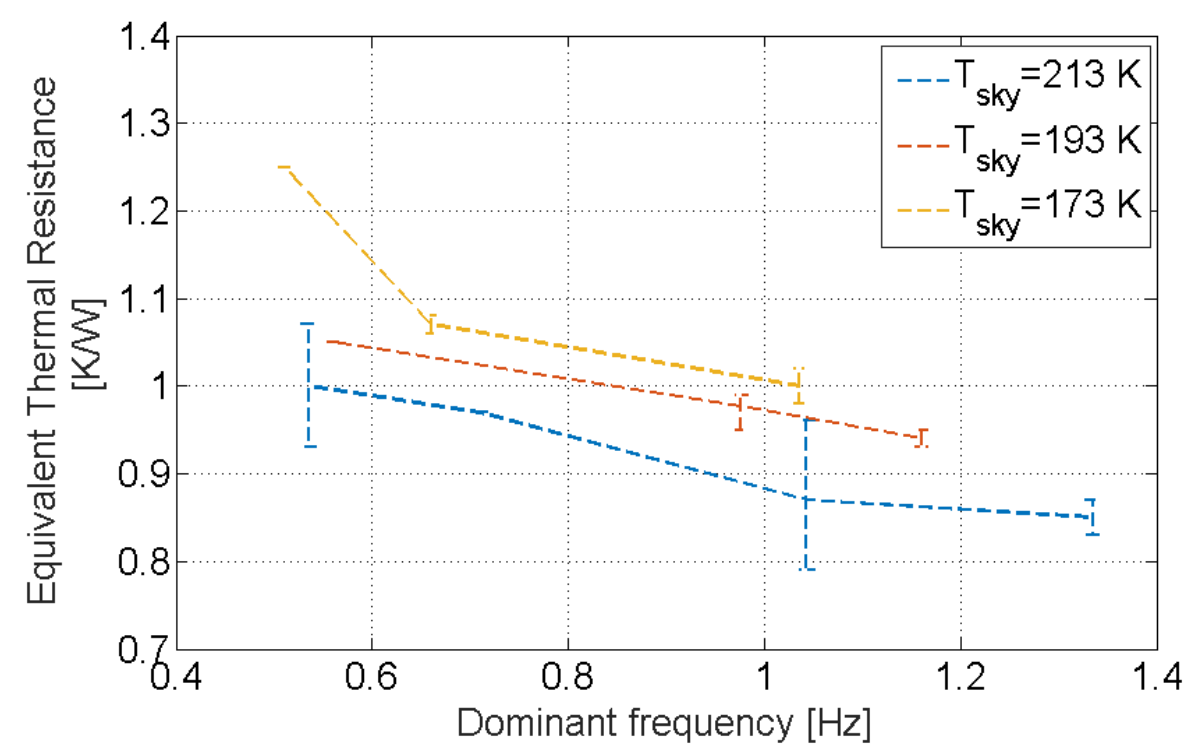

Figure 14: Effect of the oscillation frequency on the equivalent thermal resistance for the three $\mathbf{T}_{\text {sky }}$ tested.

\section{Conclusions}

An existing CLPHP test-cell already successfully tested in previous ground and microgravity experimental campaigns has been converted from an apparatus designed for forced convection cooling to a pure radiative cooling. A thermal-vacuum characterisation of the system, which can be embedded in flat surfaces for space applications, has been carried out at different temperatures of the environment $\left(\mathrm{T}_{\text {sky }}\right)$ in only radiative heat transfer conditions between the test-cell and the environment. Fluid pressure measurements coupled with the frequency analysis allowed to characterize the effect of the cold source temperature on the device operational limits and efficiency. The main outcomes are resumed here below:

- For the first time a Radiating PHP has been successfully tested in space-equivalent thermal conditions (according to ECSS);

- The Start-Up is hindered by the environment temperature of the PHP. No activation is recorded during the pre-heating phase at $4.69 \mathrm{~W} / \mathrm{cm}^{2}$; the minimum start-up heat flux increases for a decreasing $\mathrm{T}_{\text {sky }}$, Start-Up occurs at higher input power levels as $\mathrm{T}_{\text {sky }}$ decreases; Decreasing $\mathrm{T}_{\text {sky }}$ causes the blockage at higher power inputs;

- The time-frequency analysis revealed two recognizable trends related to the oscillation dominant frequency: it increases with the power input and decreases with the $\mathrm{T}_{\text {sky; }}$

- The performance and operating range of PHPs designed for space applications may be overestimated if PHPs are tested under ambient temperature.

- The radiative configuration affects mostly the PHP performance due to the lower operative temperatures needed to obtain a sensible heat rejection, rather than the heat transfer mode itself. 


\section{Appendix A: Vacuum condition to obtain purely radiative heat transfer}

To obtain a purely radiative heat exchange between the radiator and the thermal vessel, it is required that the atmosphere inside the vacuum chamber is characterized by a molecular flux regime. This condition corresponds to a value of the Knudsen number $\left(K_{n}\right)$ of 10 . The vacuum level that guarantees a molecular flux in the TVC can be obtained from the definition of $\mathrm{K}_{\mathrm{n}}$.

$$
\mathrm{K}_{\mathrm{n}}=\lambda / \mathrm{D}=\mathrm{K}_{\mathrm{b}} \mathrm{T} /\left(2 \pi \sigma^{2} \mathrm{PD}\right)^{0.5}
$$

where: $\lambda$ is the mean free path of a particle, $D$ is the reference dimension of the vacuum chamber to be evacuated, $K_{b}$ is the Boltzmann constant $(\mathrm{J} / \mathrm{K}), T$ is the absolute temperature, $\sigma$ is the collisional cross-section of nitrogen particles $(\mathrm{m})$ as the principal component of the ambient atmosphere and $P$ is the pressure to be evaluated $(\mathrm{Pa})$. The values adopted for the parameters and the required TVC pressure are listed in Table 6.

Table 6: Parameters for the estimation of the TVC pressure

\begin{tabular}{c|c|c|c|c|c}
$\mathbf{K}_{\mathbf{b}}(\mathbf{J} \mathbf{~ K - 1})$ & $\mathbf{T} \mathbf{( K )}$ & $\boldsymbol{\sigma}_{\mathbf{N} 2}(\mathbf{m})$ & $\mathbf{D}(\mathbf{m})$ & $\mathbf{K}_{\mathbf{n}}$ & $\mathbf{P}(\mathbf{m b a r})$ \\
\hline $1.3807 \cdot 10^{-23}$ & 213 & $1.30 \cdot 10^{-10}$ & 1.5 & 10 & $2.6 \cdot 10^{-5}$
\end{tabular}


Appendix B: Scalogram and Power spectrum for cases from 2 to 6 in Table 4

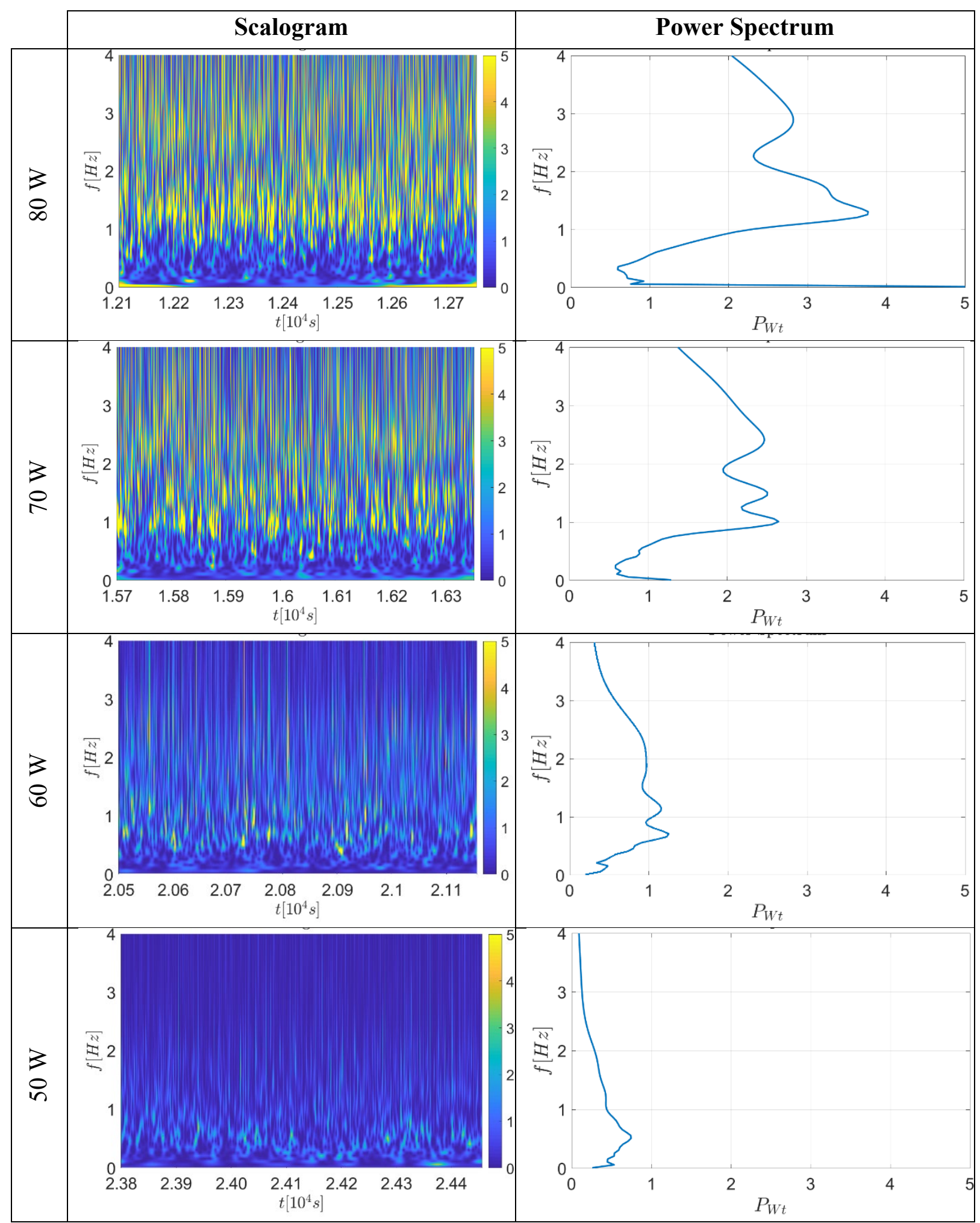

Figure 15: Scalogram and power spectrum for the power inputs of Test Case 2 analysed before the blockage $\left(T_{\text {sky }}=213 \mathrm{~K}\right)$ 


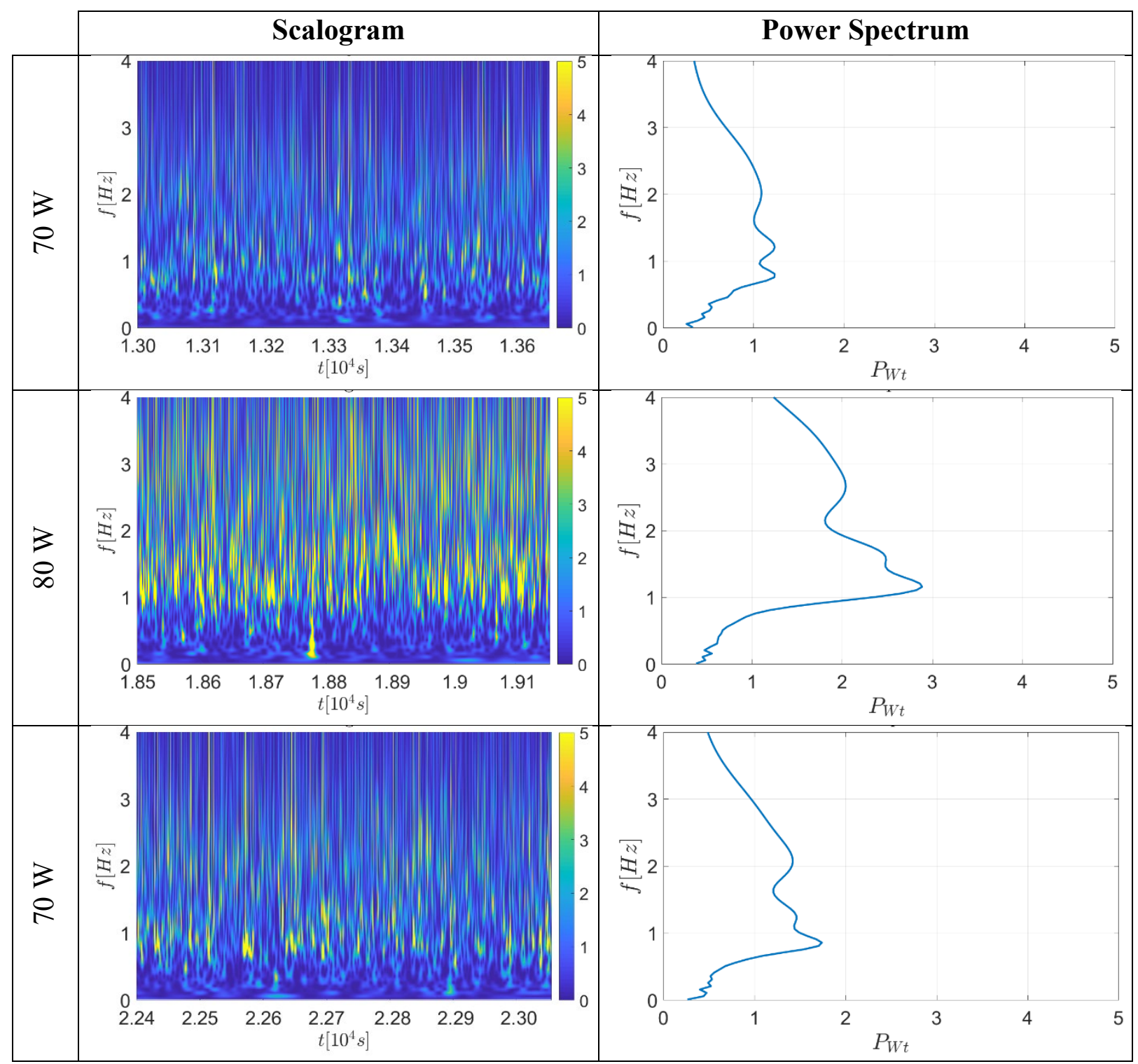

Figure 16: Scalogram and power spectrum for the power inputs of Test Case 3 analysed before the blockage $\left(T_{\text {sky }}=193 \mathrm{~K}\right)$ 


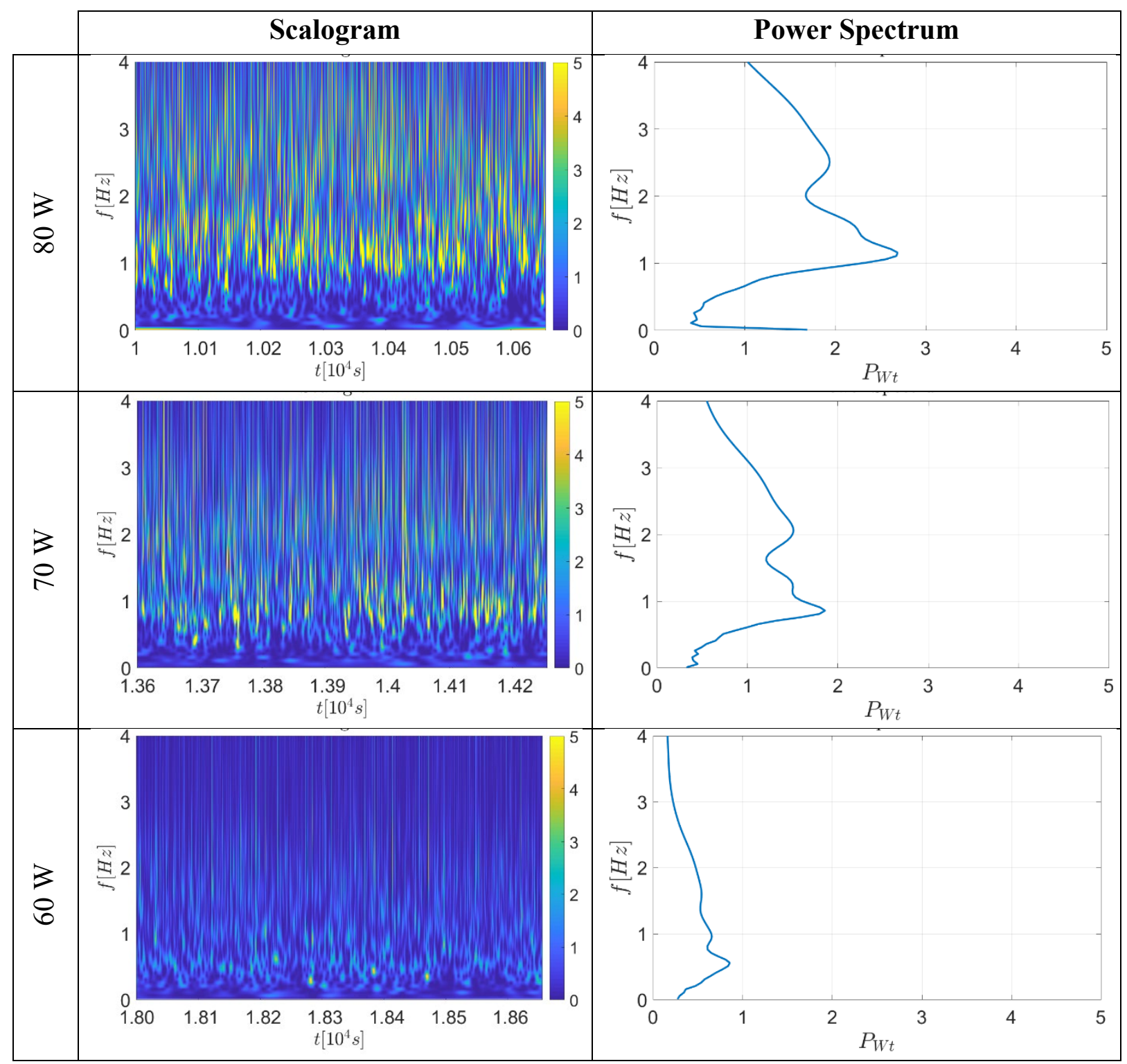

Figure 17: Scalogram and power spectrum for the power inputs of Test Case 4 analysed before the blockage $\left(T_{\text {sky }}=193 K\right)$ 


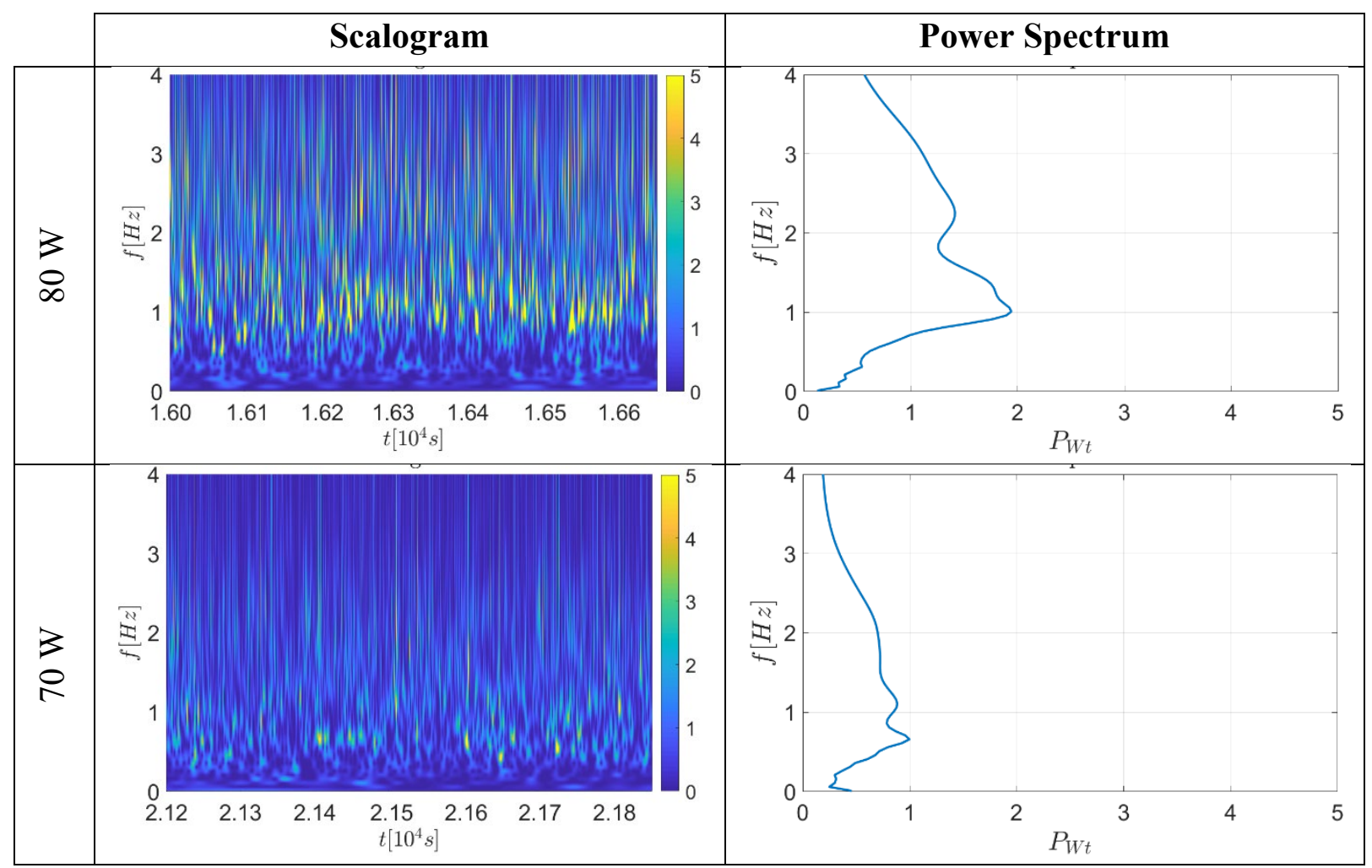

Figure 18: Scalogram and power spectrum for the power inputs of Test Case 5 analysed before the blockage $\left(T_{\text {sky }}=193 \mathrm{~K}\right)$ 


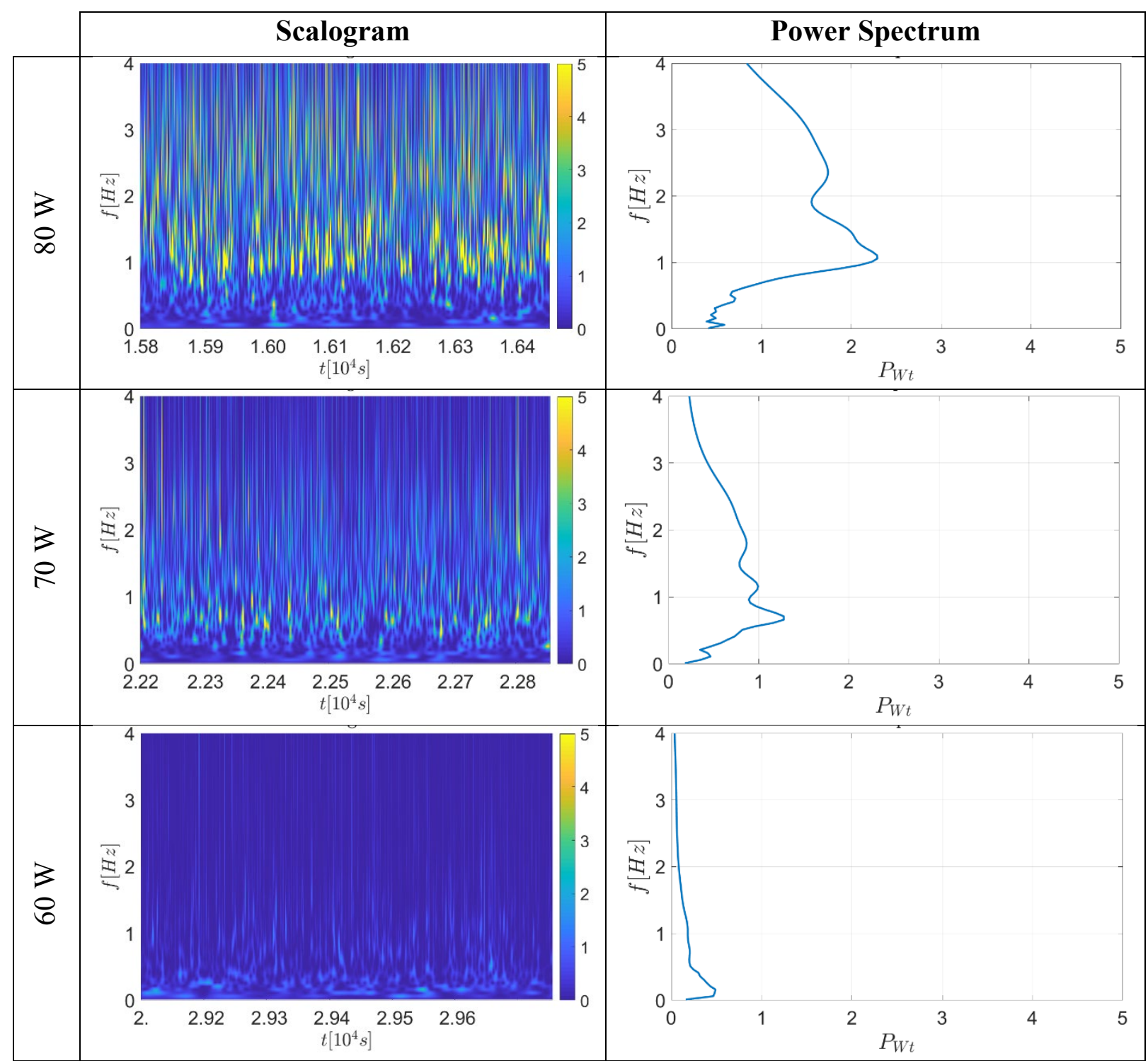

Figure 19: Scalogram and power spectrum for the power inputs of Test Case 5 analysed before the blockage $\left(T_{\text {sky }}=193 \mathrm{~K}\right)$

\section{Acknowledgments}

The present work has been carried forward in the framework of the ESA MAP Project INWIP (4000115115/15/NL/PG). The tests have been performed in the facilities of Aerospazio Tecnologie s.r.l. (CEO Fabrizio Scortecci). The authors would like to thank Edoardo Mancini and Luca Bianchi for the technical support.

\section{Nomenclature}

$\begin{array}{lll}\text { Symbol } & \text { Quantity } & \text { SI Unit } \\ d_{c r} & \text { PHP critical inner diameter } & \mathrm{m} \\ D & \text { Vacuum Chamber reference dimension } & \mathrm{m} \\ k & \text { Thermal conductivity } & \mathrm{W} / \mathrm{mK} \\ K_{b} & \text { Boltzman constant } & \mathrm{J} / \mathrm{K} \\ K_{n} & \text { Knudsen number } & {[-]} \\ f_{A c} & \text { Acquisition frequency } & \mathrm{Hz}\end{array}$




$\begin{array}{lll}\bar{f}_{D} & \text { Dominant frequency } & \mathrm{Hz} \\ h_{l v} & \text { Latent heat of vapor } & \mathrm{J} / \mathrm{kg} \\ N_{W t} & \text { Number of samples } & {[-]} \\ P & \text { Pressure } & \mathrm{Pa} \\ P_{W t} & \text { Power spectrum } & {[-]} \\ \dot{Q} & \text { Heat Load } & \mathrm{W} \\ Q_{e v} & \text { Heat of vaporization } & \mathrm{J} \\ R_{e q} & \text { Equivalent thermal resistance } & \mathrm{K} / \mathrm{W} \\ T_{a i r} & \text { Cooling air temperature } & \mathrm{K} \\ T_{f l u i d} & \text { Fluid temperature } & \mathrm{K} \\ T_{s k y} & \text { Environment temperature (TVC sky) } & \mathrm{K} \\ \bar{T}_{e v} & \text { Evaporator mean Temperature } & \mathrm{K} \\ \bar{T}_{c o} & \text { Condenser mean Temperature } & \mathrm{K} \\ t_{a n} & \text { Analysis time } & \mathrm{s} \\ V & \text { Volume } & \mathrm{m}^{3} \\ v & \text { Specific volume } & \mathrm{m}^{3} / \mathrm{kg} \\ \sigma & \text { Collisional cross section } & \mathrm{m} \\ \sigma_{f_{D}} & \text { Frequency domain uncertainty } & \mathrm{Hz} \\ \varepsilon & \text { Emissivity } & {[-]} \\ \lambda & \text { Mean free path } & \mathrm{m} \\ \tau & \text { Transmissivity } & {[-]} \\ & & \end{array}$

\section{References}

[1] D. W. Hengeveld, M. M. Mathison, J. E. Braun, E. A. Groll, A. D. Williams, D. W. Hengeveld, M. M. Mathison, J. E. Braun, and A. D. Williams, 'Review of Modern Spacecraft Thermal Control Technologies', HVAC\&R Res., vol. 16, no. 2, pp. 189-220, 2010.

[2] D. G. Gilmore, Spacecraft Thermal Control Handbook Volume I: Fundamental Technologies, 2nd ed., 2002.

[3] D. Reay and P. Kew, Heat Pipes: theory, design and applications, 5th ed. Oxford: Butterworth-Heinemann, 2006.

[4] Y. F. Maydanik, 'Loop heat pipes', Appl. Therm. Eng. 25 635-657.

[5] L. F. R. Romano and G. B. Ribeiro, 'Parametric evaluation of a heat pipe-radiator assembly for nuclear space power systems', Therm. Sci. Eng. Prog., vol. 13, no. December 2018, p. 100368, 2019.

[6] M. Marengo and V. Nikolayev, 'Pulsating heat pipes: experimental analysis, design and applications Marco', in Encyclopedia of Two-Phase Heat Transfer and Flow IV, vol. 1, J. R. Thome, Ed. World Scientific, 2018.

[7] H. Ma, Oscillating heat pipes. Springer New York, 2015. 
[8] H. Yang, S. Khandekar, and M. Groll, 'Performance characteristics of pulsating heat pipes as integral thermal spreaders', Int. J. Therm. Sci., vol. 48, no. 4, pp. 815-824, 2009.

[9] H. Jouhara, N. Khordehgah, S. Almahmoud, B. Delpech, A. Chauhan, and S. A. Tassou, 'Waste heat recovery technologies and applications', Therm. Sci. Eng. Prog., vol. 6, no. January, pp. 268-289, 2018.

[10] S. Rittidech and S. Wannapakne, 'Experimental study of the performance of a solar collector by closed-end oscillating heat pipe (CEOHP)', Appl. Therm. Eng., vol. 27, no. 11-12, pp. 1978-1985, 2007.

[11] R. Bruce, M. Barba, A. Bonelli, and B. Baudouy, 'Thermal performance of a meter-scale horizontal nitrogen Pulsating Heat Pipe', Cryogenics, vol. 93, no. October 2017, pp. 66$74,2018$.

[12] X. Chen, Y. Lin, S. Shao, and W. Wu, 'Study on heat transfer characteristics of ethane pulsating heat pipe in middle-low temperature region', Appl. Therm. Eng., vol. 152, no. February, pp. 697-705, 2019.

[13] D. Torresin, M. Habert, V. Mounier, F. Agostini, and B. Agostini, 'Characterisation of a novel pulsating heat pipe cooler for power electronics at extreme ambient temperatures', in Proceedings of the ASME 2015 13th International Conference on Nanochannels, Microchannels, and Minichannels, ICNMM2015, 2015.

[16] V. A. Hemadri, A. Gupta, and S. Khandekar, 'Thermal radiators with embedded pulsating heat pipes : Infra-red thermography and simulations', vol. 31, pp. 1332-1346, 2011.

[17] D. Mangini, M. Mameli, D. Fioriti, S. Filippeschi, L. Araneo, and M. Marengo, 'Hybrid Pulsating Heat Pipe for space applications with non-uniform heating patterns : Ground and microgravity experiments', Appl. Therm. Eng., vol. 126, pp. 1029-1043, 2017.

[18] V. Ayel, L. Pietrasanta, G. Lalizel, C. Romestant, Y. Bertin, and M. Marengo, 'ThermoHydraulic Analysis of Semi-Transparent Flat Plate Pulsating Heat Pipes Tested in $1 \mathrm{~g}$ and Microgravity Conditions', Microgravity Sci. Technol., vol. 31, no. 4, pp. 403-415, Aug. 2019.

[19] M. Mameli, A. Catarsi, D. Mangini, L. Pietrasanta, N. Michè, M. Marengo, P. Di Marco, and S. Filippeschi, 'Start-up in microgravity and local thermodynamic states of a hybrid loop thermosyphon/pulsating heat pipe', Appl. Therm. Eng., vol. 158, no. April, p. $113771,2019$.

[20] B. S. Taft and K. W. Irick, 'ASETS-II oscillating heat pipe space flight experiment: the first six months on orbit', Front. Heat Mass Transf., vol. 24, 2019.

[21] M. Ando, A. Okamoto, K. Tanaka, M. Maeda, H. Sugita, T. Daimaru, and H. Nagai, 
'On-orbit demonstration of oscillating heat pipe with check valves for space application', Appl. Therm. Eng., vol. 130, pp. 552-560, 2018.

[22] M. Mameli, L. Araneo, S. Filippeschi, L. Marelli, R. Testa, and M. Marengo, 'Thermal response of a closed loop pulsating heat pipe under a varying gravity force', Int. J. Therm. Sci., vol. 80, pp. 11-22, 2014.

[23] V. Ayel, L. Araneo, A. Scalambra, M. Mameli, C. Romestant, A. Piteau, M. Marengo, S. Filippeschi, and Y. Bertin, 'Experimental study of a closed loop flat plate pulsating heat pipe under a varying gravity force', Int. J. Therm. Sci., vol. 96, pp. 23-34, Oct. 2015.

[24] D. Mangini, M. Mameli, A. Georgoulas, L. Araneo, S. Filippeschi, and M. Marengo, 'A pulsating heat pipe for space applications: Ground and microgravity experiments', Int. J. Therm. Sci., vol. 95, pp. 53-63, 2015.

[25] B. S. Taft, F. F. Laun, S. M. Smith, and D. W. Hengeveld, 'Microgravity Performance of a Structurally Embedded Oscillating Heat Pipe', J. Thermophys. Heat Transf., vol. 29, no. 2, pp. 329-337, 2015.

[27] 'ECSS-Q-ST-70-04C: Thermal testing for the evaluation of space materials, processes, mechanical parts and assemblies', European Cooperation For Space Standardization, 2008.

[28] P. A. Kew and K. Cornwell, 'Correlations for the prediction of boiling heat transfer in small-diameter channels', Appl. Therm. Eng., vol. 17, no. 8-10, pp. 705-715, Aug. 1997.

[29] P. Gully, F. Bonnet, V. Nikolayev, N. Luchier, and T. Q. Tran, 'Evaluation of the vapor thermodynamic state in PHP', in 17th Int. Heat Pipe Conf., 2015.

[30] S. Jun and S. J. Kim, 'International Journal of Heat and Mass Transfer Experimental investigation on the thermodynamic state of vapor plugs in pulsating heat pipes', Int. J. Heat Mass Transf., vol. 134, pp. 321-328, 2019.

[31] V. S. Nikolayev and I. Nekrashevych, 'Vapor thermodynamics and fluid merit for pulsating heat pipe', in Joint 19th IHPC and 13th IHPS, Pisa, Italy, June 10-14, 2018.

[32] R. Perna, M. Abela, M. Mameli, A. Mariotti, L. Pietrasanta, M. Marengo, and S. Filippeschi, 'Flow characterization of a pulsating heat pipe through the wavelet analysis of pressure signals', Appl. Therm. Eng., vol. 171, no. January, p. 115128, 2020. 